\title{
IMPACT OF POWDER VARIABILITY ON THE MICROSTRUCTURE AND MECHANICAL BEHAVIOR OF SELECTIVE LASER MELTED ALLOY 718
}

\author{
Chantal K. Sudbrack ${ }^{1}$, Bradley A. Lerch ${ }^{1}$, Timothy M. Smith ${ }^{1}$, Ivan E. Locci ${ }^{1,2}$, \\ David L. Ellis ${ }^{1}$, Aaron C. Thompson ${ }^{1,3}$, Benjamin Richards ${ }^{1,4}$ \\ 1. NASA Glenn Research Center; 21000 Brookpark Road, Cleveland, OH 44135, USA \\ 2. University of Toledo; $2801 \mathrm{~W}$. Bancroft, Toledo, OH 43606, USA \\ 3. Vantage Partners; 3000 Aerospace Pkwy, Brook Park, OH 44142, USA \\ 4. Northwestern University; Department of Materials Science and Engineering, 2220 Campus \\ Drive, Evanston, IL 60208, USA
}

Keywords: 718, laser deposition, powder, high cycle fatigue, microstructure

\begin{abstract}
Powder-bed additive manufacturing processes use fine powders to build parts layer-by-layer. Alloy 718 powder feedstocks for selective laser melting (SLM) additive manufacturing are produced commercially by both gas and rotary atomization and are available typically in the 10-45 or 15-45 $\mu \mathrm{m}$ size ranges. A comprehensive investigation was conducted to understand the impact of powder variability on the microstructure and mechanical behavior of SLM 718 heat treated to Aerospace Material Specification (AMS) 5664. This study included sixteen virgin powders and three once-recycled powders within the 10-45 and 15-45 $\mu \mathrm{m}$ size ranges that were obtained from seven direct source suppliers and one reseller. Although alike as highly regular spheroids, these powders showed distinct differences in composition (especially $\mathrm{Al}, \mathrm{C}$ and $\mathrm{N}$ contents), particle size distributions, and powder features such as degree of agglomeration, fusion and surface roughness. Compositional differences expectedly had the strongest impact on microstructure. High $\mathrm{N}$ and $\mathrm{C}$ contents formed TiN-nitrides and/or $(\mathrm{Nb}, \mathrm{Ti}, \mathrm{Mo})-\mathrm{C}$ carbides on the grain boundaries, prevented recrystallization during heat treatment, and resulted in retained (001)-scalloped shaped grains that ranged from 19 to $41 \mu \mathrm{m}$ in average size. In the absence of this particle pinning, the average grain size of the heat treated SLM 718 ranged from $51 \mu \mathrm{m}$ to $90 \mu \mathrm{m}$. Room temperature tensile and high cycle fatigue (HCF) testing compared as-fabricated (AF) and low stress ground (LSG) surface conditions. Tensile testing revealed consistent behavior between the two surface conditions and amongst the powder lots. The finer grained SLM 718 builds displayed the lowest tensile properties. A SLM 718 build fabricated from a powder with eight times lower C content showed statistically better tensile properties presumably due to enhanced coarsening of $\delta-\mathrm{Ni}_{3} \mathrm{Nb}$ precipitates. The specimens from once-recycled powders had slightly higher tensile strengths and slightly higher ductility compared to their virgin equivalents; once-recycling also did not substantially degrade the mean HCF life. The LSG fatigue lives agreed with conventionally manufactured 718 data, while AF lives exhibited a knock-down due to surface roughness. The fatigue lives of AF specimens were statistically equivalent across powder lots except for one and failures typically initiated at stress concentrators associated with SLM surface asperities. Fatigue testing of low stress ground specimens result in both transgranular and within facet crack initiations. More than half of the cracks initiated from these facets for the machined condition; however, these facets appeared to be within grains that were larger-than-average in size. A nitrogen-atomized powder with fine prior particles of TiN-nitrides and $\mathrm{M}(\mathrm{Ti}, \mathrm{Nb}, \mathrm{Mo}) \mathrm{C}$ carbides from atomization on powder surfaces resulted in the best fatigue performance with segregation of these particles to the SLM 718 grain boundaries leading to higher resistance to early-stage crack propagation. Typically the fine-grained builds with minor phases along the grain boundaries did not perform well in fatigue, whereas a
\end{abstract}


larger-grain build with lower carbon content and coarser $\delta-\mathrm{Ni}_{3} \mathrm{Nb}$ precipitates showed the next best $\mathrm{HCF}$ response. Further details of the build microstructure and its impact on tensile and fatigue behavior was considered.

\section{Introduction}

For three decades, Aerojet Rocketdyne RS-25, a liquid-fuel cryogenic engine, propelled the Space Shuttle. Now, four of the RS-25 engines will power the core stage for NASA's Space Launch System (SLS), a heavy-lift launch vehicle to support deep space exploration. Alloy 718 comprises more than half of the weight of a single RS-25 engine with more than 1,500 individual parts in use in hydrogen, oxygen, and hydrogen-rich steam at temperatures ranging from $-253{ }^{\circ} \mathrm{C}$ to $760{ }^{\circ} \mathrm{C}[1]$. In an effort to reduce parts, eliminate welds and increase affordability, additive manufactured Alloy 718 is being considered by NASA for a couple dozen SLS engine components that are in limited production, with a specific focus on selective laser melted (SLM) Alloy 718.

Commercially viable Ni-based superalloys are highly alloyed with a rich microstructure. Conventional cast and wrought Alloy 718 are strengthened with coherent, intermetallic precipitates of metastable $\gamma^{\prime \prime}\left(\mathrm{DO}_{22}\right)-\mathrm{Ni}_{3} \mathrm{Nb}$ phase and with a small volume fraction $\gamma^{\prime}(\mathrm{L} 12)-\mathrm{Ni}_{3}(\mathrm{Ti}, \mathrm{Al})$ phase, which are uniformly distributed in the matrix and the distribution refined during the aging heat treatments [2]. The orthorhombic $\delta-\mathrm{Ni}_{3} \mathrm{Nb}$ precipitates are incoherent with the matrix and may nucleate at the grain boundaries or grow as platelets on the (111)-planes within grains [3]. Primary coarse Nb-rich MC-carbides, often irregular in shape, may form in Alloy 718 during solidification and high temperature solutioning $\left(>1000{ }^{\circ} \mathrm{C}\right)$ and are often distributed non-uniformly within the grains, grain boundaries and incoherent sections of twin boundaries. The secondary MCcarbides (and to a much lesser extent $\mathrm{M}_{23} \mathrm{C}_{6}$-carbides) may form along the grain boundaries during prolonged aging above $700{ }^{\circ} \mathrm{C}$ and may lead to a continuous carbide film that promotes intergranular fracture [4]. TiN nitrides may also form during solidification in the interdendritic regions; both the primary carbides and TiN nitrides are generally considered stable phases and will not change with thermal treatment at lower temperatures [3].

Alloy 718 and its derivatives have found wide use in high-temperature aerospace applications, due to a combination of good mechanical properties, environmental resistance, and workability at moderate cost [5]. Their modest content of refractory elements and intermetallic precipitate produces alloys that are weldable, which makes them promising candidates for selective laser melting (SLM) fabrication and has warranted a number of recent studies on SLM 718 [6, 7, 8, 9, 10]. To meet the full potential for aerospace applications, qualification and certification efforts are necessary [11]; NASA has released a standard [12] that considers material property development, metallurgical and part process control, and inspection for space flight hardware.

This investigation is an industry survey of 718 powders that are readily available commercially and aims to understand the impact of powder variability on build quality and performance of SLM 718. The investigation includes sixteen powder lots from eight suppliers that are produced by gas atomization or rotary atomization in argon or nitrogen. The survey results will help guide feedstock controls for future updates to the NASA standard [12], which might include quantities like percentage of fines, chemistry requirements, and/or defect tolerances. This paper focuses on select variables evaluated, including powder chemistry, particle size distributions of the powders, SLM grain and microstructure, and then discusses the relationship of these variables to the room temperature tensile properties and failure mechanisms observed for the room temperature high cycle fatigue behavior for the as-fabricated surface and low stress ground surface conditions. The full investigation [13] also discusses the static flow, rheological response, more details of the powder and build microstructure characterization and flammability testing, and includes a multi-variant correlation analysis using principal component analysis. 


\section{Experimental Methods}

Sixteen powder lots of Alloy 718 were produced either by gas atomization or rotary atomization in argon or nitrogen using industrial-scale equipment by seven commercial direct-source producers and one third party reseller (supplier A). After atomization, powders were screened to achieve various powder cuts requested and particle fines were removed using standard supplier practices. Typical shipping procedures were that screened powders were sealed under an inert environment and shipped in multiple plastic canisters containing $2.27 \mathrm{~kg}$ or $4.54 \mathrm{~kg}$ of powder. Once received by NASA, powders from a single lot were combined and transferred to two larger aluminum canisters in a glovebox under a nitrogen atmosphere for storage and to minimize plastic particulates (contaminants) from original packaging. To obtain well-blended and representative samples, the powders were tumbled for at least an hour prior to sampling for chemical analysis, microscopy, metallography, particle size analysis, morphology analysis, flow testing, rheology testing and reserve powder.

Powder chemistry was measured using an average of two analyses by a LECO CS-444-LS carbon/sulfur determinator, a LECO TC-436 N/O determinator, and a Varian Vista Pro ICP atomic emission spectrometer for boron and the metallic elements. Loose powder and metallographically prepared cross-sections of powder were imaged with a Nikon Eclipse MA200 optical microscope and a Hitachi S-4700 field emission scanning electron microscope (SEM). The Malvern Morphologi G3SE system was used to image the silhouettes of a minimum 20,000 individual powder particles per scan using transmitted illumination, automated optical image collection, scan area with $25 \mathrm{~mm}$ diameter, and a minimum feature size of 30 pixels $(0.88 \mu \mathrm{m})$. Particles with a solidity value (particle area divided by convex hull area) of less than 0.9 were excluded from the analyzed Morphologi distributions, which combined data from two separate scans. Circular-equivalent diameters were plotted on a log-scale to obtain the number-basis particle size distributions (PSDs).

Build sets from each powder lot were produced on a Concept Laser M1 SLM machine at NASA Marshall Space Flight Center (MSFC) equipped with a custom-built small-volume build box (100 mm x $100 \mathrm{~mm}$ x $80 \mathrm{~mm}$ ) using $30 \mu \mathrm{m}$ layer thickness and customized parameters that are similar to Concept Laser's recommended parameters for Alloy 718. A crosshatching scan strategy was applied, where the scanning direction was altered by $90^{\circ}$ between consecutive layers and contours applied to the perimeter to heal porosity associated with turning points. An aerial schematic to scale of the build layout is shown in Figure 1a. Each build set included five net-shaped mechanical test bars for the as-fabricated (AF) surface condition, 4 near-net shaped mechanical test bars for the low stress ground (LSG) surface condition, a full-height coupon for the greenstate condition (i.e., as-processed by SLM), and another full-height coupon for the fully heat-treated condition, all of which were built with a taper for easy snap-off from the stainless steel build plate. The diameters of the near-net shaped bars were $0.762 \mathrm{~mm}$ wider than the net shaped bars for grinding to net shape. The custom build volume required 2-3 powder refills during fabrication, which led to refill lines on test bars and coupons (Fig. 1b-c). Approximately $20 \mathrm{~kg}$ of powder completed a single build set without powder reuse. 


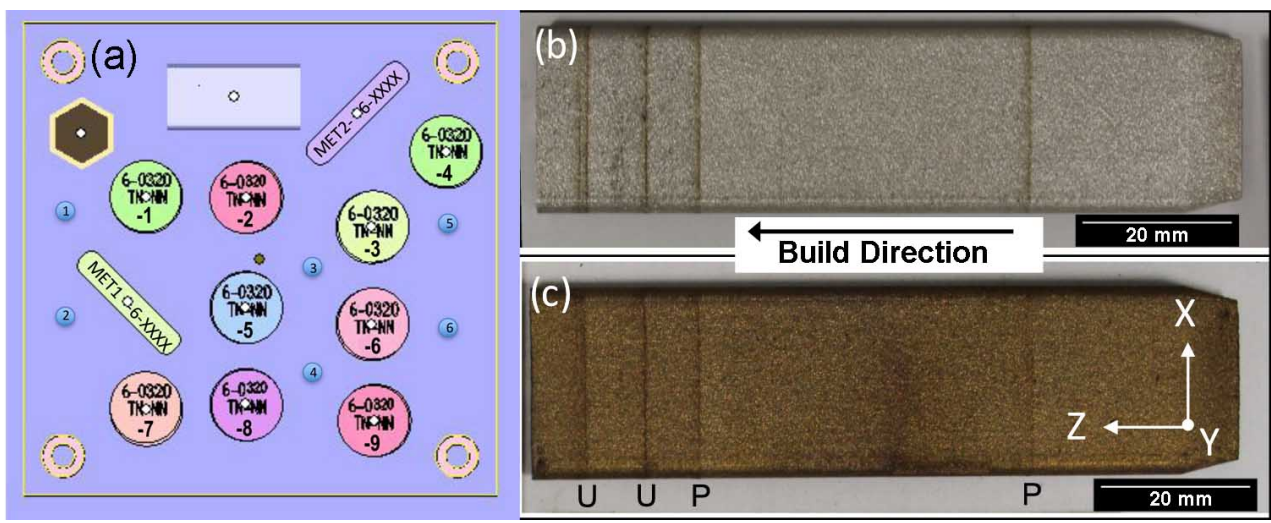

Figure 1. Alloy 718 powder investigation a) aerial schematic of SLM build plan that includes nine test bars and two fullheight coupons on a $100 \times 100 \mathrm{~mm}^{2}$ substrate; photographs of the two coupons from the build D2 once-recycled powder: $b$ ) as-processed (i.e. "green-state") and c) fully heat treated. As shown in (c), D2-R coupons had surface discontinuities from two planned (P) and two unplanned (U) restarts. Note X, Y are relative to the cross-section length and width of the coupons.

The green-state test bars and one coupon were hot isostatic pressed (HIP) at a hold temperature above $1100{ }^{\circ} \mathrm{C}$ for several hours in batches. During HIP, each specimen from a build set was wrapped with stainless steel foil to getter residual oxygen from the argon atmosphere in the HIP vessel. The test bars and specimens were then heat treated according to AMS 5664 under vacuum by NASA MSFC, which consisted of $1.25 \mathrm{~h} \mathrm{ramp}$ from $22^{\circ} \mathrm{C}$ to solutioning at $1066 \pm 14{ }^{\circ} \mathrm{C}$ for $\sim 1 \mathrm{~h}$ at 1.0-2.5 $\times 10^{-5}$ Torr + air-cool rate-equivalent, followed by $0.88 \mathrm{~h}$ ramp from $22{ }^{\circ} \mathrm{C}$ to aging at $760 \pm 8{ }^{\circ} \mathrm{C}$ for $10.0 \pm 0.5 \mathrm{~h}$ at or below $0.32-1.1 \times 10^{-5}$ Torr + furnace cool and $649 \pm 8^{\circ} \mathrm{C}$ hold until $20 \mathrm{~h}$ of total aging was reached then furnace cooled. After full heat treatment, the near net-shaped test bars were fully machined with a low stress ground and polished finish to approximately $0.2 \mu \mathrm{m}$ mean roughness in the gauge, while only the grip sections of the net-shape bars were machined by NASA MSFC.

The full-height coupons were photographed prior to sectioning to document the green-state (i.e., as-processed by SLM) and heat-treated surface conditions such as those shown in Fig. 1. The porosity measurements and large nitride size measurements were determined from images obtained with a Nikon Eclipse MA200 optical microscope using image thresholding of 5 areas from metallographically prepared XZ sections excised at mid height of full height coupon. The small nitride and carbide sizes were measured similarly on SEM images acquired at $3 \mathrm{kV}$ and $12 \mathrm{kV}$, respectively, to avoid subsurface signals using a Zeiss Auriga FIB-SEM. Linear intercept grain size distributions of these same sections were determined according to ASTM E112 linear intercept procedures using circular grid overlays on areas that were immersion etched for $360 \mathrm{~s}$ with $85 \mathrm{~mL} \mathrm{H}_{2} \mathrm{O} / 45 \mathrm{~mL} \mathrm{HCl} / 15 \mathrm{~mL} \mathrm{HNO}_{3} / 15 \mathrm{~mL} \mathrm{HF}$. Grain distributions and texture in several directions were also assessed using a Zeiss Auriga dual-beam FIB-SEM equipped with EDAX Hikari Electron Back Scatter Diffraction (EBSD) detector and TSL OIM Analyzer software. SEM imaging and EDS microanalysis was also performed on surfaces and cross-sections cited using a Hitachi S-4700 SEM or Tescan MA13 Triglav SEM.

Each test bar was photographed prior to testing to document its condition and after testing to record failure location. Tensile tests were conducted on one test bar per condition at room temperature $\left(\sim 22{ }^{\circ} \mathrm{C}\right)$ under strain control at a strain rate of $3.3 \times 10^{-4} \mathrm{~s}^{-1}$ until $2 \%$ strain. The test then continued without unloading in stroke control at an equivalent displacement rate until failure. High cycle fatigue (HCF) tests were conducted on three test bars per condition in load control at a frequency of $20 \mathrm{~Hz}$. Tests were run at $22{ }^{\circ} \mathrm{C}$ using a sinusoidal waveform at a load ratio, $\mathrm{R}_{\sigma}$, of -1 . Samples were conducted at stress levels expected to give failure in one million cycles. The required stress amplitudes were determined to be about $271 \mathrm{MPa}$ for the 
AF bars and about $464 \mathrm{MPa}$ for the LSG bars. Test bars were cycled until they broke into two pieces, or interrupted upon achieving approximately ten million cycles. Two test bars (C1-3-2 and C1-3-8) were interrupted and were subsequently retested at a higher stress level until failure. The fracture surface of each test bar was photographed optically to document the crack initiation sites and then the failure modes were evaluated more carefully using SEM to determine failure initiation sites and modes using JEOL 6100 , JEOL 840, or Hitachi S-4700 microscopes typically operated at $15-20 \mathrm{kV}$. The front of the fatigue test rig relative to the fracture surfaces was oriented at 6 o'clock position in the SEM images.

\section{Evaluation of Alloy 718 Powders}

Table 1 lists the 16 powder lots evaluated for this investigation, which were produced to composition specification for AMS 5664 by gas atomization (GA) or rotary atomization in either a nitrogen or argon atmosphere. The powder lot identifications (ID) referenced throughout this paper refer to the eight powders suppliers as A-H with the first, second, third,

Table 1. Select details of the 16 Alloy 718 powders evaluated that were produced by conventional gas-atomization (GA) or rotary atomization in either an argon or nitrogen gas environment

\begin{tabular}{|c|c|c|c|c|c|c|c|c|c|c|c|c|}
\hline ID & Alloy 718 Powders & $\begin{array}{l}\text { Requested } \\
\text { Powder } \\
\text { Cut }(\mu \mathrm{m})\end{array}$ & Process & Gas & $\begin{array}{l}\text { Al } \\
(w t . \%)\end{array}$ & $\begin{array}{l}\mathrm{Cr} \\
(\mathrm{wt} . \%)\end{array}$ & $\begin{array}{l}\text { C } \\
\text { (wt.\% } \\
\text { ppm) }\end{array}$ & $\begin{array}{l}\mathrm{N} \\
\text { (wt.\% } \\
\text { ppm) }\end{array}$ & $\begin{array}{l}\% \text { of } \\
D<7 \\
\mu \mathrm{m}\end{array}$ & $\begin{array}{l}\mathrm{D}(10) \\
*(\mu \mathrm{m})\end{array}$ & $\begin{array}{l}\mathrm{D}(50) \\
(\mu \mathrm{m})\end{array}$ & $\begin{array}{l}\mathrm{D}(90) * \\
(\mu \mathrm{m})\end{array}$ \\
\hline A1 & Supplier 1, Powder 1 & $15-45$ & GA & Ar & 0.395 & 18.82 & 350 & 325 & 11.4 & 17.6 & 25.1 & 40.6 \\
\hline A2 & Supplier 1, Powder 2 & $10-45$ & GA & $\mathrm{Ar}$ & 0.505 & 18.94 & 240 & 90 & - & (3.4) & $(7.0)$ & $(17.0)$ \\
\hline A3 & Supplier 1, Powder 3 & $10-45$ & GA & $\mathrm{Ar}$ & 0.380 & 18.17 & 280 & 331 & 37.3 & $\begin{array}{l}8.5 \\
(2.6)\end{array}$ & $\begin{array}{l}20.1 \\
(10.6)\end{array}$ & $\begin{array}{l}35.1 \\
(30.9)\end{array}$ \\
\hline B1 & Supplier 2, Powder 1 & $15-45$ & Rotary & Ar & 0.465 & 19.00 & 50 & 25 & - & (3.8) & $(9.5)$ & (26.9) \\
\hline $\mathrm{C} 1$ & Supplier 3, Powder 1 & $15-45$ & GA & $\mathrm{N}$ & 0.565 & 17.45 & 390 & 1395 & 23.2 & 24.1 & 29.1 & 40.0 \\
\hline D1 & Supplier 4, Powder 1 & $16-45$ & GA & Ar & 0.480 & 19.02 & 330 & 122 & 12.2 & 13.5 & 23.7 & 38.0 \\
\hline D2 & Supplier 4, Powder 2 & $11-45$ & GA & $\mathrm{Ar}$ & 0.495 & 19.11 & 305 & 115 & 4.2 & 12.8 & 17.9 & 30.7 \\
\hline E1 & Supplier 5, Powder 1 & $10-45$ & GA & $\mathrm{N}$ & 0.090 & 17.71 & 960 & 1220 & 33.7 & 11.8 & 23.8 & 41.5 \\
\hline E2 & Supplier 5, Powder 2 & $10-45$ & GA & $\mathrm{N}$ & 0.705 & 19.11 & 470 & 2770 & 9.6 & 12.8 & 19.1 & 32.1 \\
\hline $\mathrm{F} 1$ & Supplier 6, Powder 1 & $15-45$ & GA & $\mathrm{Ar}$ & 0.345 & 18.25 & 330 & 607 & 16.5 & 13.9 & 23.0 & 38.6 \\
\hline $\mathrm{F} 2$ & Supplier 6, Powder 2 & $10-45$ & GA & $\mathrm{Ar}$ & 0.390 & 18.37 & 340 & 370 & 8.0 & 10.3 & 17.7 & 34.9 \\
\hline G1 & Supplier 7, Powder 1 & $0-22$ & GA & $\mathrm{Ar}$ & 0.440 & 18.82 & 330 & 207 & - & $(3.4)$ & $(6.0)$ & $(10.5)$ \\
\hline G2 & Supplier 7, Powder 2 & $11-45$ & GA & Ar & 0.455 & 18.77 & 360 & 176 & 1.3 & 11.2 & 14.6 & 23.8 \\
\hline G3 & Supplier 7, Powder 3 & $16-45$ & GA & Ar & 0.485 & 18.77 & 390 & 199 & 8.1 & 17.6 & 25.3 & 39.5 \\
\hline G4 & Supplier 7, Powder 4 & $45-90$ & GA & Ar & 0.475 & 18.77 & 330 & 246 & 89.9 & 8.5 & 74.0 & 91.4 \\
\hline H1 & Supplier 8, Powder 1 & $10-45$ & GA & $\mathrm{Ar}$ & 0.355 & 18.52 & 215 & 562 & 78.2 & 9.1 & 18.7 & 31.6 \\
\hline
\end{tabular}

* The $\mathrm{D}(10), \mathrm{D}(50)$ and $\mathrm{D}(90)$ values are the $10^{\text {th }}, 50^{\text {th }}$ and $90^{\text {th }}$ percentiles of the number-basis PSDs. The non-parenthetical values exclude the circular-equivalent diameters (D) less than $7 \mu \mathrm{m}$, whereas the values in parentheses include them because the primary peaks of these distributions include sub-sized particles. 
fourth lots supplied 1,2,3 and 4. Fourteen of the 16 powders were acquired in powder cuts common to SLM with about half in the wider 10-45 $\mu \mathrm{m}$ range, the other half in the narrow 15-45 $\mu \mathrm{m}$ range and with two additional ones in an undersized cut, G1(0-22), and an oversized cut, G4(45-90), from supplier G.

Powders from all suppliers except from supplier E met AMS 5664 composition and are within narrow weight percent compositional ranges of 0.35-0.51 Al, 0-0.039 C, 18.1-19.2 Cr, 18.0-19.2 Fe, 2.9-3.1 Mo, 4.8-5.2 Nb, 0.8-1.0 Ti, balance Ni and trace impurities. The E1 powder is outside the acceptable AMS 5664 ranges for $\mathrm{Al}, \mathrm{Cr}$, Fe content with a composition of Ni-0.09 Al-0.096 C-17.72 Cr-21.49 Fe-2.93 Mo-4.86 Nb-0.91 Ti wt.\%, while E2 powder meets AMS 5664; however, it has higher contents of $\mathrm{Al}$ and $\mathrm{C}$ than the powders from the other seven suppliers. The variation in $\mathrm{Al}, \mathrm{Cr}, \mathrm{C}$ and $\mathrm{N}$ contents when significant (Table 1) influences the $\gamma^{\prime}$-precipitates, carbides and nitrides as discussed in more detail below. The $G$ series powders show statistically equivalent compositions, which gives an opportunity to separate composition from size effects.

In addition to composition differences, the Alloy 718 powders evaluated show unique features in morphology, shape and size. The visual comparison of loose powders in Fig. 2 highlights the differences in surface roughness, satellites, fusion, and size ranges. All the powders exhibit fairly smooth and spheroidal-shaped particles, demonstrating that the powders are distinct and the powder suppliers had varying success in particle fine screening as quantifiable in the number-basis PSDs shown in Fig. 3. The B1 powder produced by rotary atomization is particularly smooth with few satellites; while the D1, E1, $\mathrm{H} 1$ powders are rougher and show agglomeration. The $\mathrm{H} 1$ powder has the highest degree of agglomeration, where both the $\mathrm{H} 1$ and G4 powders are above $75 \%$ of sub-sized particles within the distribution. The $\mathrm{C} 1$ powder shows more particle fusion than the other powders.

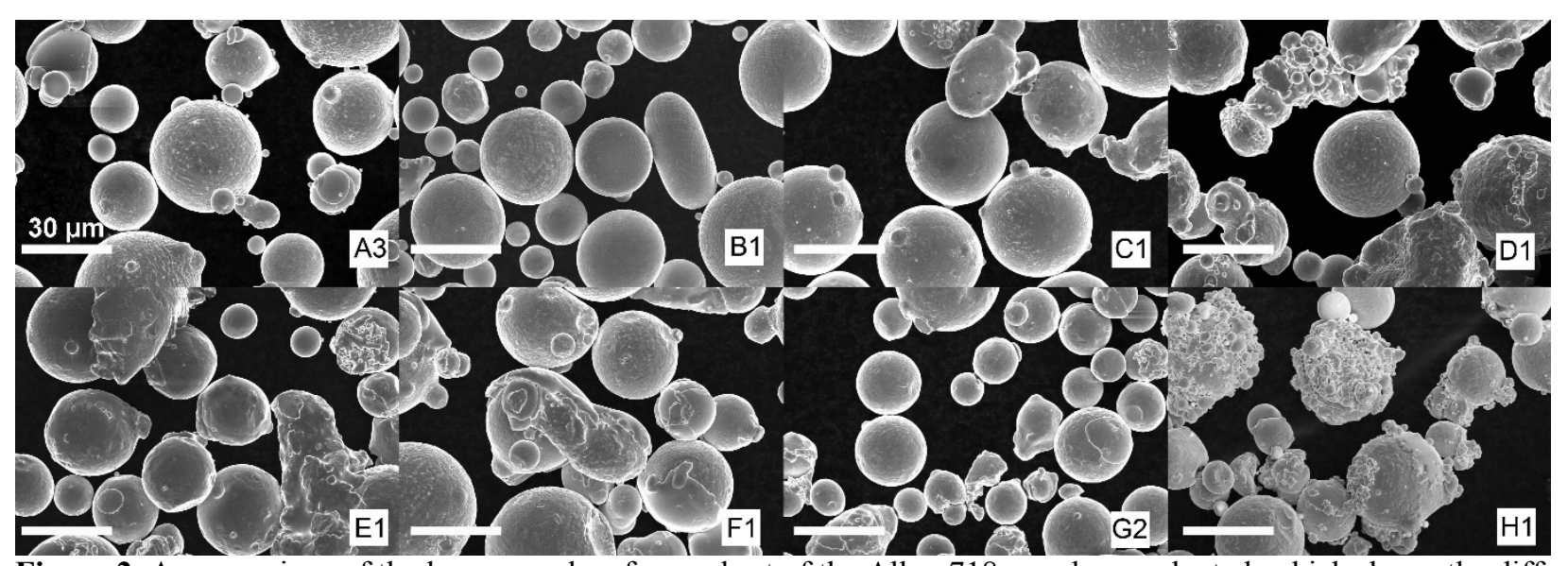

Figure 2. A comparison of the loose powders for a subset of the Alloy 718 powders evaluated, which shows the differences in agglomeration, surface roughness, satellites, fusion, and particle size ranges. 


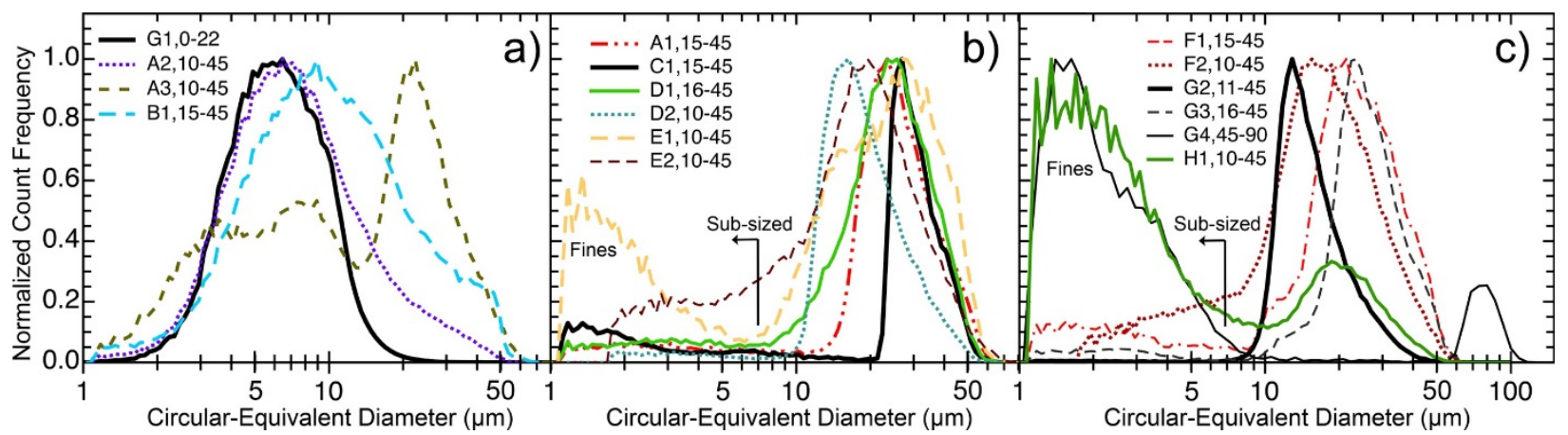

Figure 3. Number-basis particle size distributions (PSDs) for a) the G1 powder in a 0-22 $\mu$ m cut compared to powders that are under-sized to their cuts and the A3 powder with a trimodal distribution; b) roughly half of the regularly-sized powders; c) the G4 powder in a 45-90 $\mu \mathrm{m}$ cut compared to the remaining regularly-sized powders. Typical powder cuts for SLM 718 include $10-45 \mu \mathrm{m}$ and $15-45 \mu \mathrm{m}$.

The circular-equivalent diameter data in Table1, D(10), D(50), and D(90), and the number-basis PSDs in Figure 3 demonstrate that some suppliers provide better accuracy in powder cut size ranges and ranges may be skewed. These numberbasis PSDs are more sensitive to particle fine counts than volume-basis ones (e.g. laser spectral data). The size range for the G1 powder is within the 0-22 $\mu \mathrm{m}$ range (Fig. 3a), whereas the A2(10-45) and B1(15-45) powders are under-sized. These wide distributions for $\mathrm{A} 2$ and $\mathrm{B} 1$ are unimodal with half of the particles (i.e., the median $\mathrm{D}(50)$ values) below $7.0 \mu \mathrm{m}$ and $9.5 \mu \mathrm{m}$ and $\mathrm{D}(90)$ values that extend to $17.0 \mu \mathrm{m}$ and $26.9 \mu \mathrm{m}$, respectively. As shown in Fig. 3b-c, the E1, H1, and G4 powders are bimodal with a valley at $7 \mu \mathrm{m}$ between peaks and a strong peak at about $1.5 \mu \mathrm{m}$ that corresponds to the high percentage of fines present within these powders. For the regular-sized powder cuts, the $\mathrm{D}(10), \mathrm{D}(50)$, and $\mathrm{D}(90)$ values within Table 1 exclude the sub-sized particles with $\mathrm{D}<7 \mu \mathrm{m}$ in order to separate the contributions of the sub-sized particles from the primary peak. The remaining regular-sized powders are unimodal with $\mathrm{D}(50)$ ranging from $14.6 \mu \mathrm{m}(\mathrm{G} 2)$ to 29.1 $\mu \mathrm{m}(\mathrm{C} 1)$, with the exception of the A3 powder, which shows an unusual, trimodal distribution with maxima at $\sim 3 \mu \mathrm{m}, \sim 8 \mu \mathrm{m}$ and $\sim 20 \mu \mathrm{m}$.

\section{Selective Laser Melted Builds and Microstructure}

SLM fabrication was employed to fabricate eighteen build sets from 15 different 718 powders (Table 2). Most powders from this investigation were procured off-the-shelf in $22 \mathrm{~kg}$ amounts; second lots in larger quantities of $>500 \mathrm{~kg}$, were procured from suppliers D, E, and F, which allows the impact of a single powder reuse to be assessed for SLM Alloy 718 . To study once-recycled reuse, the powder in both the build and overflow chambers were removed, sieved with a $100 \mu \mathrm{m}$ sieve, and returned to the dose chamber with no additional mixing. The once-recycled build sets are identified as D2-R, E2-R and F2-R. There were challenges in SLM fabrication for the off-nominal powder cuts evaluated. The G1 powder lot with 0-22 $\mu \mathrm{m}$ particles clumped and spread poorly; the attempt at SLM fabrication was not successful. The G4 powder lot with 45-90 $\mu \mathrm{m}$ particles did build, but the test bars and specimens exhibited poor interlayer bonding, which led to compromised mechanical integrity not discussed further here. For the G3 build set, a test bar was lost and another compromised due to a build fault during normal operation on the trailing side of the build plate. 
Table 2. Select microstructural details of SLM builds of various Alloy 718 powders listed in Table 1

\begin{tabular}{|c|c|c|c|c|c|c|c|c|c|c|}
\hline $\begin{array}{c}\text { ID } \\
(\mathrm{Gas})\end{array}$ & $\begin{array}{c}\text { Green-State } \\
\text { (GS) } \\
\text { Porosity (\%) }\end{array}$ & $\begin{array}{c}\text { GS Pore } \\
\text { Diameter } \\
(\mu \mathrm{m})\end{array}$ & $\begin{array}{l}\text { Full HT } \\
\text { Porosity } \\
\quad(\%)\end{array}$ & $\begin{array}{l}\text { FHT Pore } \\
\text { Diameter } \\
\quad(\mu \mathrm{m})\end{array}$ & $\mathrm{Rx}^{*}$ & $\begin{array}{l}\text { Grain } \\
\text { Size } \\
(\mu \mathrm{m})\end{array}$ & $\begin{array}{c}\text { Nitride } \\
V_{\mathrm{f}} * *(\%)\end{array}$ & $\begin{array}{c}\text { Nitride Mean } \\
\text { Diam. } * *(\mathrm{~nm})\end{array}$ & $\begin{array}{l}\text { Carbide } \\
V_{f}(\%)\end{array}$ & $\begin{array}{c}\text { Carbide Mean } \\
\text { Diam. }(\mu \mathrm{m})\end{array}$ \\
\hline A1 & $0.19 \pm 0.09$ & $12.1 \pm 3.0$ & $<0.02$ & $3.3 \pm 0.4$ & Yes & $70 \pm 14$ & 0.32 & $122 \pm 18$ & 0.038 & $0.56 \pm 0.18$ \\
\hline $\mathrm{A} 2$ & $0.69 \pm 0.23$ & $21.9 \pm 4.0$ & $<0.02$ & $3.3 \pm 0.3$ & Yes & $57 \pm 11$ & 0.23 & $106 \pm 9$ & 0.10 & $0.56 \pm 0.09$ \\
\hline A3 & $0.19 \pm 0.15$ & $12.0 \pm 3.3$ & $<0.02$ & $3.5 \pm 0.6$ & Yes & $90 \pm 40$ & 0.38 & $104 \pm 12$ & 0.023 & $0.47 \pm 0.19$ \\
\hline B1 & $0.19 \pm 0.05$ & $11.5 \pm 2.3$ & $<0.02$ & $3.4 \pm 0.4$ & Yes & $68 \pm 14$ & 0.17 & $97 \pm 6$ & 0.002 & $0.24 \pm 0.14$ \\
\hline $\begin{array}{l}\mathrm{C} 1 \\
(\mathrm{~N})\end{array}$ & $0.14 \pm 0.07$ & $10.9 \pm 2.3$ & $<0.02$ & $3.1 \pm 0.6$ & No & $36 \pm 13$ & 0.54 & $127 \pm 26$ & 0.021 & $0.37 \pm 0.11$ \\
\hline D1 & $0.10 \pm 0.08$ & $9.6 \pm 2.6$ & $\begin{array}{c}0.036 \pm \\
0.023\end{array}$ & $5.1 \pm 1.2$ & Yes & $53 \pm 7$ & 0.22 & $90 \pm 3$ & 0.09 & $0.56 \pm 0.13$ \\
\hline D2 & $0.46 \pm 0.21$ & $12.5 \pm 2.1$ & $\begin{array}{c}0.024 \pm \\
0.007\end{array}$ & $3.8 \pm 0.4$ & Yes & $51 \pm 10$ & 0.26 & $94 \pm 8$ & 0.07 & $0.59 \pm 0.17$ \\
\hline $\begin{array}{l}\text { E1 } \\
(N)\end{array}$ & $0.5 \pm 0.3$ & $14.5 \pm 3.0$ & $<0.02$ & $3.3 \pm 0.5$ & No & $22 \pm 3$ & 0.49 & $80 \pm 16$ & 0.25 & $0.47 \pm 0.05$ \\
\hline $\begin{array}{l}\text { E2 } \\
(N)\end{array}$ & $0.13 \pm 0.08$ & $8.2 \pm 1.7$ & $<0.02$ & $3.8 \pm 1.1$ & No & $32 \pm 3$ & $\begin{array}{c}0.87 \\
(0.13) \\
\end{array}$ & $\begin{array}{c}141 \pm 11 \\
(7.8 \pm 1.0 \mu \mathrm{m}) \\
\end{array}$ & 0.039 & $0.43 \pm 0.05$ \\
\hline F1 & $0.15 \pm 0.09$ & $9.5 \pm 2.0$ & $<0.02$ & $3.0 \pm 0.3$ & Yes & $88 \pm 28$ & 0.47 & $92 \pm 9$ & 0.012 & $0.40 \pm 0.10$ \\
\hline F2 & $0.22 \pm 0.08$ & $3.55 \pm 0.26$ & $0.09 \pm 0.05$ & $3.01 \pm 0.18$ & Yes & $64 \pm 18$ & 0.35 & $110 \pm 11$ & 0.054 & $0.49 \pm 0.10$ \\
\hline $\mathrm{G} 2$ & $0.14 \pm 0.07$ & $9.3 \pm 1.8$ & $<0.02$ & $5.0 \pm 0.6$ & Yes & $63 \pm 10$ & 0.27 & $90 \pm 5$ & 0.058 & $0.59 \pm 0.18$ \\
\hline G3 & $0.14 \pm 0.07$ & $10.0 \pm 1.9$ & $<0.02$ & $4.5 \pm 1.4$ & Yes & $71 \pm 19$ & 0.34 & $105 \pm 4$ & 0.110 & $0.49 \pm 0.08$ \\
\hline G4 & $0.3 \pm 0.3$ & $11.5 \pm 3.1$ & $0.07 \pm 0.09$ & $6.5 \pm 2.3$ & Yes & $39 \pm 9$ & 0.29 & $114 \pm 14$ & 0.058 & $0.59 \pm 0.17$ \\
\hline H1 & $0.19 \pm 0.11$ & $8.3 \pm 1.5$ & $0.06 \pm 0.04$ & $4.3 \pm 0.6$ & Mix & $41 \pm 6$ & $\begin{array}{c}0.42 \\
(0.013)\end{array}$ & $\begin{array}{c}112 \pm 11 \\
(6.9 \pm 0.4 \mu \mathrm{m})\end{array}$ & 0.009 & $0.33 \pm 0.10$ \\
\hline $\mathrm{D} 2-\mathrm{R}$ & $0.11 \pm 0.06$ & $9.8 \pm 2.6$ & $0.05 \pm 0.06$ & $3.1 \pm 0.4$ & Yes & $63 \pm 9$ & 0.24 & $94 \pm 4$ & 0.08 & $0.63 \pm 0.18$ \\
\hline $\begin{array}{l}\text { E2-R } \\
(\mathrm{N})\end{array}$ & $1.1 \pm 0.4$ & $12.9 \pm 1.6$ & $\begin{array}{c}0.031 \pm \\
0.015 \\
\end{array}$ & $3.1 \pm 0.4$ & No & $19 \pm 6$ & $\begin{array}{c}1.03 \\
(0.13) \\
\end{array}$ & $\begin{array}{c}137 \pm 21 \\
(8.0 \pm 1.2 \mu \mathrm{m})\end{array}$ & 0.056 & $0.49 \pm 0.09$ \\
\hline F2-R & $0.78 \pm 0.24$ & $18.0 \pm 2.4$ & $<0.02$ & $3.4 \pm 0.3$ & Yes & $70 \pm 14$ & 0.24 & $87 \pm 8$ & 0.019 & $0.53 \pm 0.25$ \\
\hline
\end{tabular}

* Rx denotes recrystallization; ** $\mathrm{V}_{\mathrm{f}}$ denotes volume fraction, and parenthetical values in these columns are measurements for the large nitrides observed optically for the three builds sets.

SLM full-height coupons, as shown in Fig. 1b, and the mechanical test bars appear shiny after fabrication and are golden in color after heat treatment due to a modest amount of oxidation during the HIP treatment. SLM build sets were fabricated successfully with a custom, small-volume machine configuration, which unlike the regular configuration, required 2 powder refills of the piston, leading to a restart layer across the build set for each refill (e.g., prominent lines on coupons in Fig. 1b). In addition to the 2 refills, about half of the powders triggered one or more piston failures with the $\mathrm{H} 1$ powder triggering five failures during its build set, possibly due to its high fine content. These planned and unplanned restarts were mitigated by following the MSFC-suggested restart procedure of adding a thin flux coat of powder (about $1 / 2$ of a layer thickness) and performing 3 full layer melts to reinitialize the build. When properly mitigated, the restart layer did not result in a crack initiation site during the tensile and HCF testing. 


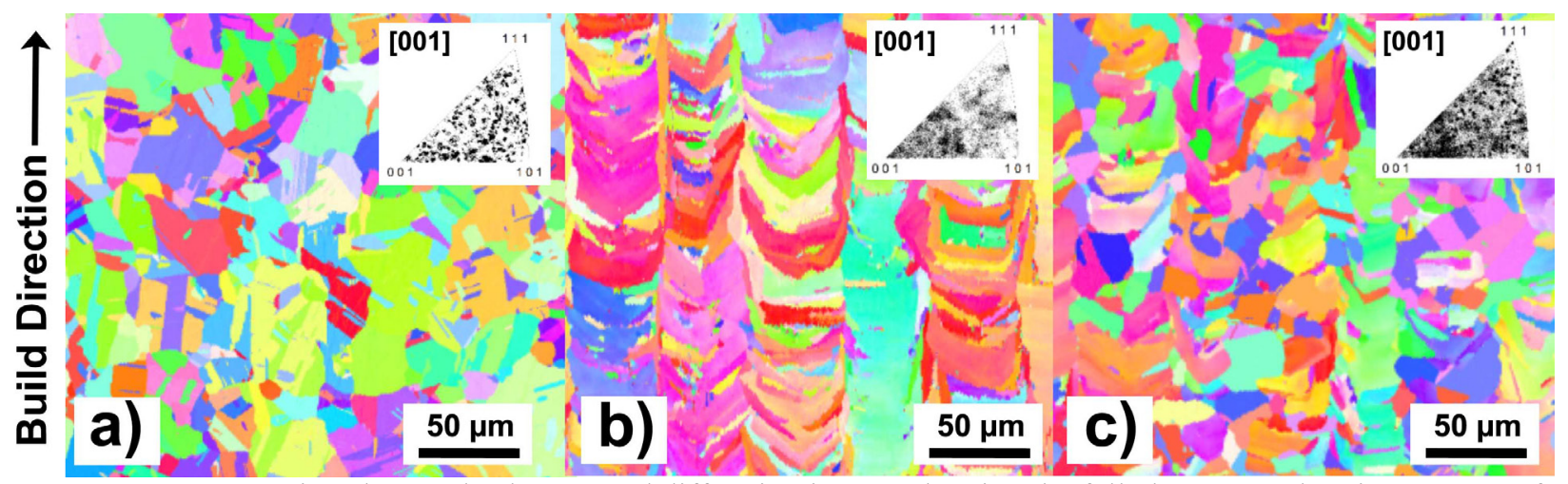

Figure 4. Representative electron back-scattered diffraction images showing the fully heat-treated grain structure of SLM 718 specimens with a) full recrystallization with high percentage of twins; b) no recrystallization due to particle pinning; c) a mixture where some areas underwent recrystallization (H1 powder). Recrystallization of the as-fabricated SLM grains shown in (a) occurs during the high temperature HIP heat treatment in SLM processed 718 for most compositions investigated here.

Post-processing heat treatment in SLM 718 aims to reduce the high residual stresses (see [14]) and grain texture [10] associated with fabrication, as well as refining the microstructure for mechanical performance. Post-processing heat treatment may also be beneficial by minimizing undesirable Laves phases through solutioning [9] and eliminating large pores with the HIP treatment that may lead to fatigue debits. Due to reasonable build parameters, the as-processed SLM 718 exhibits a modest level of micron-sized pores throughout most of the green-state builds, less than $0.3 \%$ and $12.2 \mu \mathrm{m}$ average pore diameter (Table 2). Notably higher levels of porosity $(>0.75 \%)$ are observed for two of the three build sets from the powders sets that are once-recycled. The porosity is reduced with HIP to manageable levels with most fully heat-treated builds exhibiting less than $0.02 \%$ porosity with an average pore diameter of less than $4.5 \mu \mathrm{m}$.

Prolonged HIP treatment of as-processed SLM 718 above $1100{ }^{\circ} \mathrm{C}$ leads to recrystallization of textured grains in SLM 718 [9]. Fourteen of the 18 build sets post heat-treatment exhibit equiaxed grains with little to no texture (Fig. 4a) that can be attributed to recrystallization during HIP; the powders associated with all of these builds were atomized in argon. Excluding the G4 set, which exhibited irregular build quality, the mean linear intercept grain sizes ranged from $51 \mu \mathrm{m}$ to $90 \mu \mathrm{m}$ for these fully heat-treated builds (Table 2). In contrast, the build sets that are fabricated from the three powder lots atomized in nitrogen show scalloped (001)-texture grains characteristic of as-processed SLM 718 (Fig. 4b). The H1 build set, which is from a powder lot atomized in argon, is partially recrystallized with some texture (Fig. 4c) and shows some areas with the scalloped grain structure. A closer examination below establishes that the retained grain structure after heat treatment is due to particle pinning of the grain boundaries (GBs) by highly stable minor phases during the high temperature heat treatment.

Two populations, "large" and "small", of titanium-based nitrides are observed after full heat treatment for the SLM build sets as quantified in Table 2. The "large" nitride population is comprised of faceted particles with 7-8 $\mu \mathrm{m}$ average diameters that are sparsely distributed in three builds sets: E2, E2-R and H1 powder lots. Figure 5 shows, for the E2 lot, that similarly-sized TiN particles are present in the powder, the green-state coupon and the fully heat-treated coupon. The large nitrides precipitate during the gas atomization and continue to be stable over the localized, rapid melting of the SLM powderbed and the post processing heat treatment. The nitrogen content for N-atomized E2 powder is very high at $2770 \mathrm{wt} . \% \mathrm{ppm}$ 


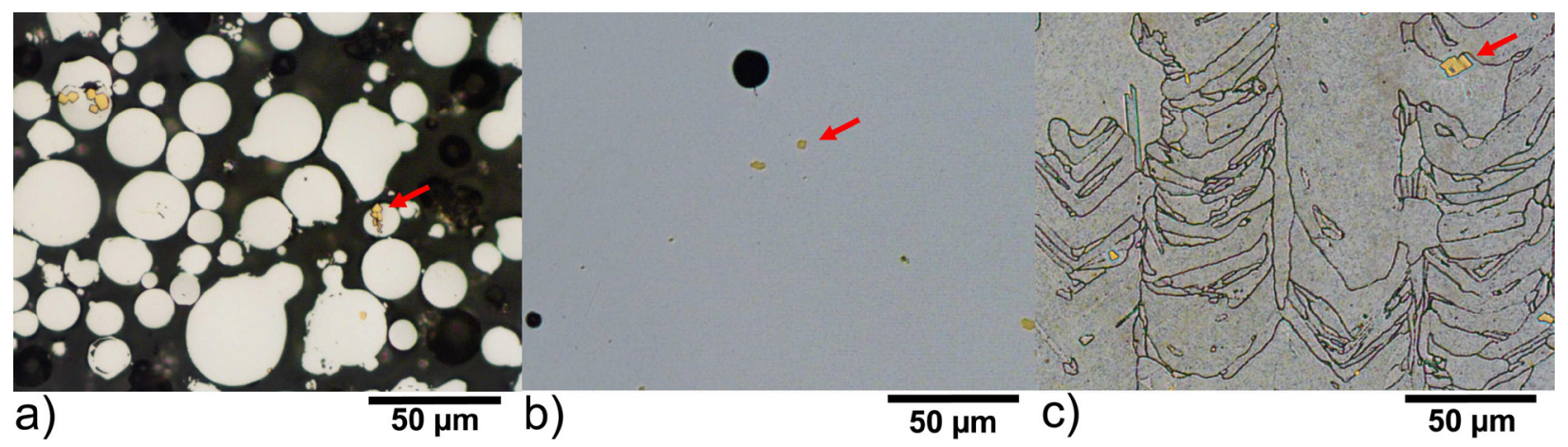

Figure 5. Optical images showing $\sim 8 \mu \mathrm{m}$ diameter nitrides that image with a gold color from E2 a) cross-sectioned powder, b) green-state SLM coupon, c) etched SLM coupon after heat treatment. The $2770 \mathrm{ppm} w t . \% \mathrm{~N}$ content for the E2 powder was the highest (Table 1), and it was 1 of 3 powders atomized in $\mathrm{N}$.

(Table 1), about double the content of the two other N-atomized powders at 1395 and 1220 wt.\% ppm for $\mathrm{C} 1$ and E1 lots, respectively. Large nitrides are found at $0.13 \%$ volume fraction $\left(\mathrm{V}_{\mathrm{f}}\right)$ for both the first and second once-recycled build sets of the $\mathrm{E} 2$ powder, but not for the $\mathrm{C} 1$ or $\mathrm{E} 1$ build sets, which contain fairly high $\mathrm{N}$ contents. The build fabricated from the $\mathrm{H} 1$ powder with a $\mathrm{N}$ content of $562 \mathrm{wt} \%$ ppm also shows sporadically large nitrides that are similarly in size, but ten times less frequent, $\mathrm{V}_{\mathrm{f}}=0.013 \%$, than the $\mathrm{E} 2$ and $\mathrm{E} 2-\mathrm{R}$ builds. The second nitride population, or "small" nitrides consists of spheroidal particles that range in average diameter from $80 \mathrm{~nm}$ to $141 \mathrm{~nm}$ and that are 50 to100 times smaller than the large nitrides. These small nitrides are distributed uniformly throughout all the builds sets, including the B1 powder which contained only $25 \mathrm{wt} . \% \mathrm{ppm}$ of $\mathrm{N}$. As the nitrogen content of the powders increases, the mean diameter and $\mathrm{V}_{\mathrm{f}}$ of the nitrides also increases (Table 2).

The series of images in Figure 6 shows the differences in minor phase distributions between builds and helps elucidate the role of the Ti-based nitrides and carbides in pinning GBs after post processing the C1, E1, E2 and H1 build sets. The small spheroidal particles that image with dark contrast are the small TiN nitrides that tend to distribute uniformly in most builds, while the brightly imaged particles are refractory-based carbides and $\mathrm{Nb}$-rich $\delta$-precipitates. Like in the majority of lots atomized in argon, the GBs in the B1 build are mostly free of nitrides and carbides allowing the as-processed grains to recrystallize. The platelet particles imaged along the $\mathrm{B} 1 \mathrm{~GB}$ are $\delta-\mathrm{Ni}_{3} \mathrm{Nb}$ precipitates that nucleate heterogeneously, and are present along some GBs for the various SLM 718 investigated here, despite the fast air cool equivalent from the solutioning heat treatment that aims to help suppress $\delta$-formation. The bright spot on the right edge of the EDS maps in Fig. $6 \mathrm{~b}$ is a typical $0.5 \mu \mathrm{m}$ MC-carbide present intergranularly and intragranularly in all builds. Typical to this type of carbide, the MC-carbide that is mapped is enriched in Nb, Ti, and Mo, but not Cr. In contrast to all other SLM 718 builds evaluated, the heat-treated GBs in $\mathrm{C} 1$ are ornamented with a fine dispersion of Ti-based nitrides and carbides, which are less than several hundred nanometers in diameter (Fig. 6). As shown in the EDS maps of GB area for a $\mathrm{C} 1$ build (Fig. 6b), the fine nitrides along the GBs are enriched in Ti only (dark-contrast), whereas the fine GB carbides (light-contrast) are mostly enriched in Ti but also contain some $\mathrm{Nb}$ and $\mathrm{Mo}$. The enrichment in $\mathrm{Ti}$ and $\mathrm{Nb}$ within the carbides suggests that they are likely carbides with the $\mathrm{MC}$ structure. Both the fine nitrides and carbides are attributed to prior particles that form on powder surface during the gas atomization in nitrogen. During the development of powder metallurgy, nitrogen-atomized Alloy 625 in the 1980s, such prior particles, identified as titanium MC-carbides and nitrides, were found to heavily ornament the GBs in HIP consolidated 


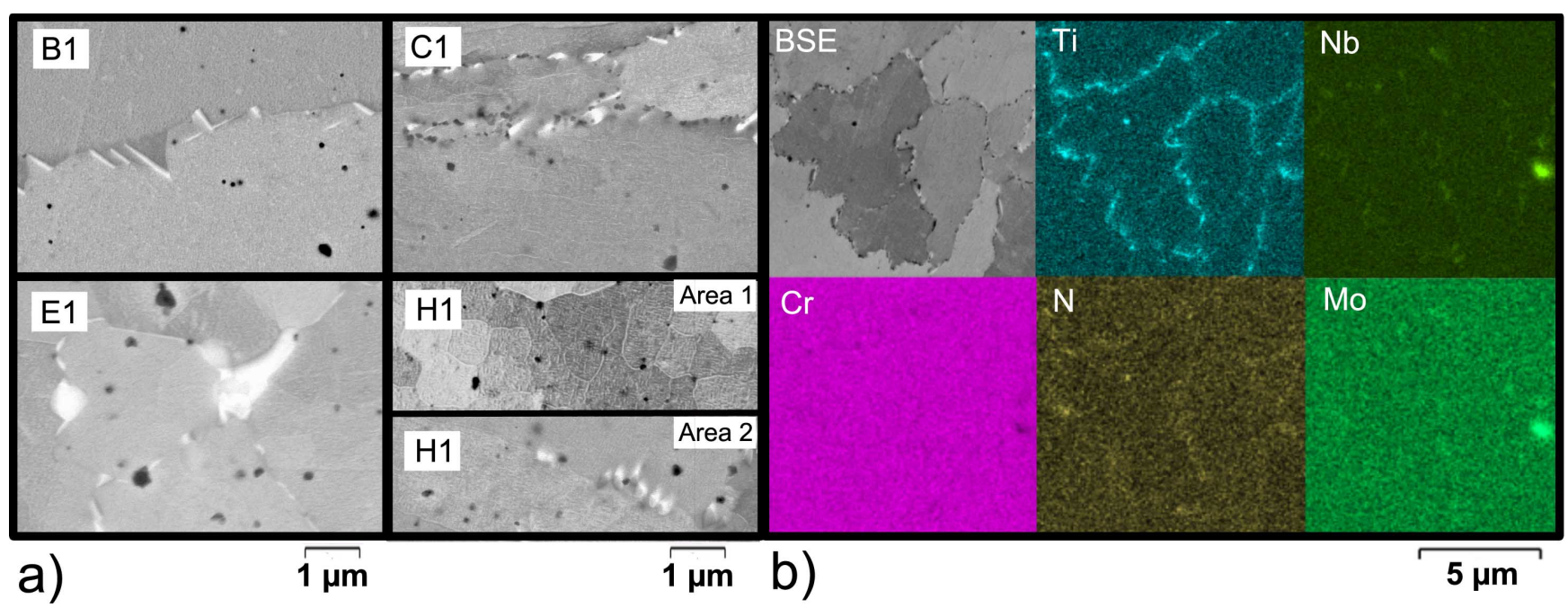

Figure 6. Grain boundary areas from the SLM 718 fully heat-treated builds obtained from powder lots with varying carbon and nitrogen contents (Table 1) that show a) differences in dark-contrast TiN nitride and bright-contrast carbide and $\delta$-precipitate distributions. EDS maps from the b) fully heat-treated $\mathrm{C} 1$ build, establishing a mix of TiN nitrides and $(\mathrm{Ti}, \mathrm{Nb}, \mathrm{Mo}) \mathrm{C}$ carbides along the grain boundaries.

alloy and lead to a decrease in ductility [15]. In vacuum-atomized Alloy 690, more modest distributions on GBs led to no degradation in ductility and better high-temperature strength than the wrought alloy [16]. Although also atomized in nitrogen, the E series builds exhibits a similar number density of nitrides at the GBs as in the bulk in contrast to the GB decoration in C1. There are few prior particles in the examination of the powder surfaces from the E series with SEM. The GBs in the heattreated builds appear instead to be decorated with closely-spaced, film-like carbides that vary in size from $100 \mathrm{~nm}$ to a couple microns (Fig. 6a), indicating these carbides are mainly responsible for GB pinning in the E series builds. In contrast to E series powders, the $\mathrm{H} 1$ powder has a much more modest $\mathrm{C}$ content (215 wt.\% ppm) and moderate $\mathrm{N}$ content (562 wt.\% ppm). The fully heat treated H1 builds exhibit areas which are fine-grained and other areas that are coarse-grained, such as the areas labelled as 1 and 2 in Fig. 6a, respectively. The GBs within the coarse grained areas are similar to those in the large-grained SLM builds; that is, GBs with occasional $\delta$-needles and carbides yet mostly free of minor phases. The GBs in the fine grained areas appear to sometimes image brightly, which may be related to GB segregation of refractory elements. Sometimes the areas contain narrow ( $\sim 50 \mathrm{~nm}$ width) film-like phases along the GBs, which are not well resolved with the EDS maps in SEM. Further investigation that includes higher resolution GB analysis with TEM is needed to resolve the mechanism that leads to the bimodal grain distribution. It is plausible that the bimodal distribution may be associated with transport of the lighter fines $(\sim 75 \%)$ to the outer edge of the melt pool, which may alter the composition of these edge areas from surface absorbants and segregants and contribute to differences in GB chemistry.

Figure 7 compares the AF surfaces of a F1 and $\mathrm{H} 1$ test bar after full HIP and heat treatment and prior to testing. The H1 series exhibited better fatigue lives for the as-fabricated surface condition as discussed in more detail below, leading to further surface characterization of the test bars. Both test bars show parallel ridges that extend the length of the test bars; these ridges are a result of a non-optimized contours (perimeter melt scans) during SLM fabrication. During the HIP treatment, the test bars were individually wrapped with stainless steel foil to getter residual oxygen present in the argon atmosphere. All the test bars except from the H1 build set show a bright appearance in gauge with gold hue due to slight oxidation during HIP, Fig. 7a. The $\mathrm{H} 1$ bars show a different and distinctive surface appearance, Fig. $7 \mathrm{~b}$, with a mixture of dull grey towards the radius and silvery grey in the gauge section. On the test bar surfaces, there is a distribution of unmelted particles adhered, as 
well as carbon-based contamination (dark contrast in Fig. 7c-f). Qualitatively, the surface area covered by unmelted particles seems greater on the F1 bar than on the $\mathrm{H} 1$ bar, which may be a result of a better incorporation in $\mathrm{H} 1$ of its high frequency of fines (and low frequency of large particles on a count basis) into the melt pool. The grey color of the H1 test bars may indicate increased oxidation on these surfaces. EDS evaluation in SEM revealed that the primary external oxide for several bars with the gold hue is $\mathrm{Al}_{2} \mathrm{O}_{3}$; the $\mathrm{H} 1$ bars also exhibit an $\mathrm{Al}_{2} \mathrm{O}_{3}$ external scale; however, the external oxide is decorated with a high number density of irregular-shaped (Nb,Ti)-based particles that are sub-micron in size (inset Fig. 7f), causing a surface that is less smooth on this length scale. The source of the grey color and (Nb,Ti)-particles needs further investigation. The composition of $\mathrm{H} 1$ powder is consistent with the other powders, such that the oxidation behavior would be approximately equivalent for the same thermal cycles and atmosphere. The gold-hued D1 and G4 build sets were part of the same HIP batch as the $\mathrm{H} 1$ build set, which indicates the residual oxygen present overall during HIP treatment was not significantly different than the other HIP runs. Perhaps the possible increase in surface oxidation of the H1 bars may also be associated with their proximity to the argon inlet. Perhaps the $\mathrm{H} 1$ bars were not wrapped as well in the foil and that led to increased oxidation. Perhaps the H1 bars were dirty (e.g. high levels of carbon contamination) and the dirt led to surface reaction during the high temperature exposure.

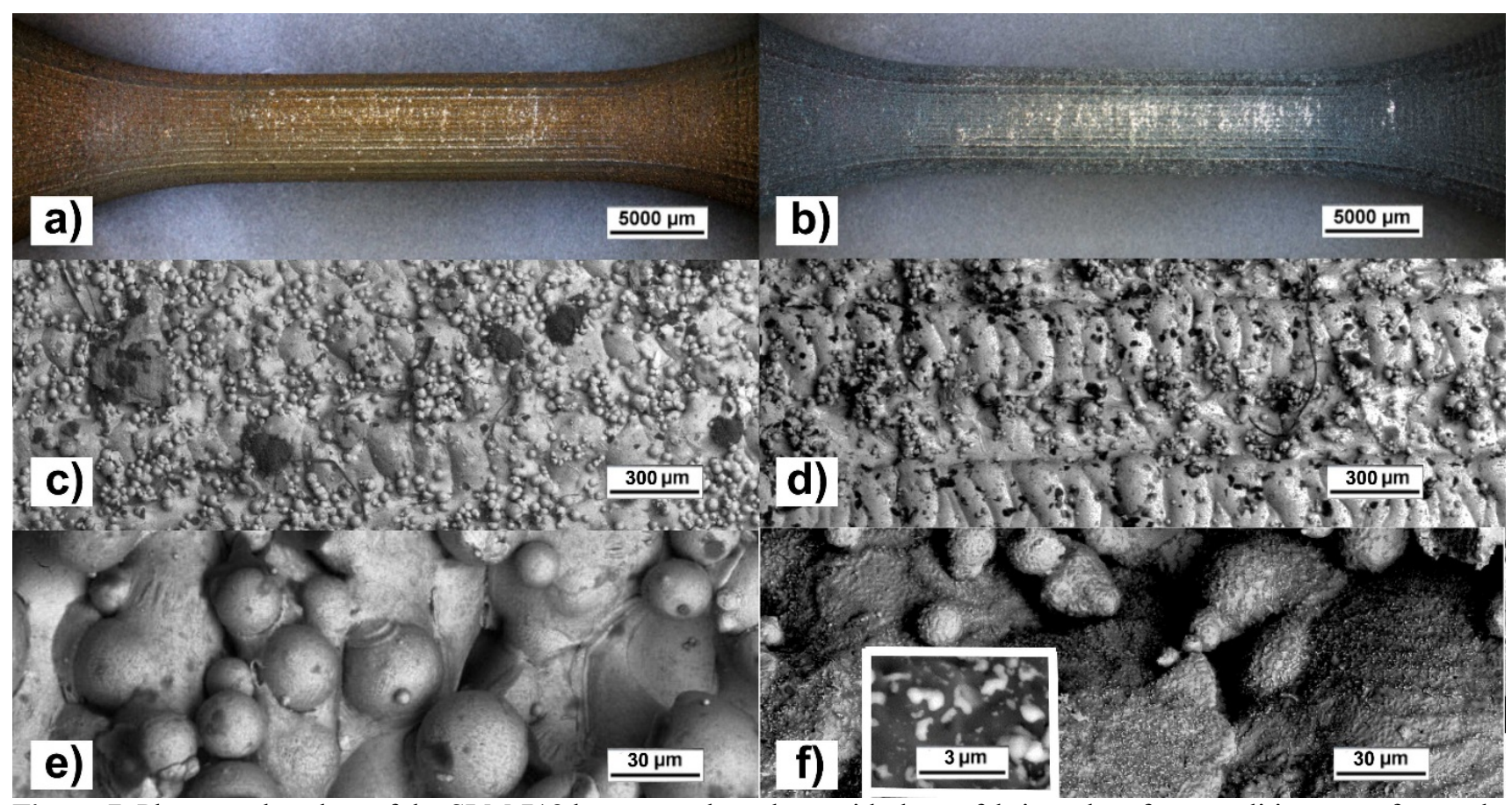

Figure 7. Photographs taken of the SLM 718 heat treated test bars with the as-fabricated surface condition manufactured from the a) F1 and b) $\mathrm{H} 1$ powder lots show the representative golden hue of the test bar surfaces and the atypical gray hue observed only for the $\mathrm{H} 1$ test bars. Beneath each photograph, the magnified surface areas imaged with back-scattered electrons in c)-f) show ridges in the test bars that result from non-optimized contours in SLM, the distribution of unmelted particles adhered to the surfaces, and carbon-based contamination (dark areas). The $\mathrm{H} 1$ test bar in $\mathrm{f}$ ) has a rougher surface than the $\mathrm{F} 1$ test bar in e) due to a high number density of (Nb,Ti)-based particles that are sub-micron in size. 


\section{Mechanical Testing Results}

Table 3 summarizes the room temperature tensile properties for each powder lot tested in the as-fabricated (AF) and low stress ground (LSG) surface condition in rank order by ultimate tensile strength (UTS). The strengths for a given powder lot are ranked in a similar position regardless of whether they are AF or LSG samples, indicating that surface finish is not a factor in the strength of these builds. Test bars fabricated from the recycled powders have slightly higher strengths by 5-10 $\mathrm{MPa}$ and slightly higher ductilities by $0.9-1.9 \%$ than those made from their virgin equivalents. While these differences are small, neither the strength nor ductility are degraded and seem to improve by first powder recycling for SLM 718. For the AF surface condition, the various powder lots fall within a statistical group with a mean UTS of $1310 \pm 40 \mathrm{MPa}$. This group

Table 3. The room temperature properties, rank ordered by UTS determined from a single tensile test per surface condition for each powder lot*

\begin{tabular}{|c|c|c|c|c|c|c|c|c|c|c|c|c|c|}
\hline \multicolumn{7}{|c|}{ Tensile Properties for As-Fabricated (AF) Surface Condition } & \multicolumn{7}{|c|}{ Tensile Properties for Low Stress Ground Surface Condition } \\
\hline $\begin{array}{c}\text { TestBar } \\
\text { ID }\end{array}$ & $\begin{array}{c}\text { Elastic } \\
\text { Modulus } \\
(\mathrm{GPa})\end{array}$ & $\begin{array}{c}0.02 \% \\
\text { Yield } \\
\text { Strength } \\
(\mathrm{MPa})\end{array}$ & $\begin{array}{c}0.2 \% \\
\text { Yield } \\
\text { Strength } \\
(\mathrm{MPa})\end{array}$ & $\begin{array}{c}\text { Ultimate } \\
\text { Tensile } \\
\text { Strength } \\
(\mathrm{MPa})\end{array}$ & \begin{tabular}{|c|} 
Elongation \\
to Failure \\
$(\%)$
\end{tabular} & $\begin{array}{c}\text { Reduc- } \\
\text { tion of } \\
\text { Area } \\
(\%)\end{array}$ & $\begin{array}{c}\text { TestBar } \\
\text { ID }\end{array}$ & $\begin{array}{c}\text { Elastic } \\
\text { Modulus } \\
(\mathrm{GPa})\end{array}$ & $\begin{array}{c}0.02 \% \\
\text { Yield } \\
\text { Strength } \\
(\mathrm{MPa})\end{array}$ & $\begin{array}{c}0.2 \% \\
\text { Yield } \\
\text { Strength } \\
(\mathrm{MPa}) \\
\end{array}$ & $\begin{array}{l}\text { Ultimate } \\
\text { Tensile } \\
\text { Strength } \\
(\mathrm{MPa})\end{array}$ & $\begin{array}{c}\text { Elongation } \\
\text { to Failure } \\
\quad(\%)\end{array}$ & $\begin{array}{c}\text { Reduc- } \\
\text { tion of } \\
\text { Area } \\
(\%)\end{array}$ \\
\hline $\mathrm{B} 1-3$ & 184 & 1023 & 1180 & 1383 & 24.0 & 26.3 & B1-4 & 198 & 1066 & 1236 & 1439 & 24.1 & 36.8 \\
\hline $\mathrm{G} 2-9$ & 188 & 996 & 1140 & 1348 & 23.8 & 24.2 & G3-6 & 194 & 1029 & 1188 & 1404 & 25.7 & 35.1 \\
\hline $\mathrm{G} 3-7 * *$ & 182 & - & - & - & - & - & $\mathrm{G} 2-4$ & 192 & 1035 & 1190 & 1402 & 27.3 & 39.9 \\
\hline A3-9 & 181 & 978 & 1135 & 1344 & 24.4 & 26.9 & A3-4 & 189 & 1031 & 1181 & 1391 & 26.4 & 33.8 \\
\hline D1-9 & 185 & 954 & 1109 & 1336 & 24.8 & 27.6 & D1-4 & 191 & 1000 & 1151 & 1377 & 24.8 & 39.7 \\
\hline D2-R-9 & 184 & 971 & 1110 & 1326 & 23.1 & 32.2 & D2-R-4 & 193 & 1001 & 1150 & 1376 & 26.4 & 37.4 \\
\hline D2-9 & 189 & 959 & 1100 & 1319 & 23.9 & 29.4 & F2-R-3 & 187 & 846 & 1141 & 1372 & 24.5 & 39.9 \\
\hline F2-R-9 & 182 & 963 & 1100 & 1314 & 23.5 & 27.3 & D2-4 & 192 & 1001 & 1145 & 1371 & 25.8 & 38.9 \\
\hline A2-7 & 182 & 936 & 1076 & 1309 & 25.0 & 32.9 & A2-4 & 193 & 991 & 1133 & 1367 & 26.2 & 34.8 \\
\hline F2-9 & 183 & 948 & 1087 & 1302 & 24.5 & 33.4 & F2-2 & 191 & 1006 & 1140 & 1362 & 24.9 & 34.4 \\
\hline A1-9 & 183 & 925 & 1083 & 1301 & 23.6 & 31.1 & A1-4 & 186 & 1000 & 1136 & 1354 & 26.8 & 34.4 \\
\hline F1-9 & 184 & 948 & 1082 & 1293 & 24.9 & 25.7 & F1-2 & 193 & 988 & 1128 & 1349 & 25.1 & 30.1 \\
\hline E2-R-9 & 184 & 908 & 1044 & 1285 & 19.2 & 25.3 & E2-R-4 & 189 & 958 & 1084 & 1342 & 21.2 & 23.3 \\
\hline C1-9 & 176 & 954 & 1083 & 1281 & 22.5 & 34.2 & H1-4 & 190 & 982 & 1108 & 1340 & 25.9 & 36.7 \\
\hline E2-9 & 184 & 881 & 1024 & 1271 & 19.4 & 27.7 & E2-4 & 191 & 950 & 1076 & 1336 & 19.9 & 29.1 \\
\hline H1-9 & 183 & 911 & 1045 & 1265 & 21.1 & 26.4 & $\mathrm{C} 1-4$ & 178 & 990 & 1135 & 1333 & 24.0 & 32.7 \\
\hline E1-3 & 166 & 831 & $\underline{999}$ & $\underline{1233}$ & 20.3 & 25.3 & E1-4 & 170 & 900 & 1039 & 1276 & 23.2 & 27.1 \\
\hline \multicolumn{3}{|c|}{ Minimum AMS 5664} & 1034 & 1241 & 10 & 12 & \multicolumn{3}{|c|}{ Minimum AMS 5664} & 1034 & 1241 & 10 & 12 \\
\hline
\end{tabular}

* Two AF tests built with E supplier's powder, which are underlined, did not meet AMS 5664

** G3-7 test failed at $(0.9 \%, 1132 \mathrm{MPa})$ from lack of fusion defects due to a build failure, and is not a valid test. 
is bound by the G2 powder lot on the upper end and by the H1 powder lot on the lower end. Only two lots are outside of the standard deviation, where the response for B1 and E1 powder lots are the strongest (1383 MPa) and weakest (1233 MPa), respectively. A similar response is observed for the LSG condition, but the mean UTS is slightly higher at $1365 \pm 29 \mathrm{MPa}$. The main group is bound by the $\mathrm{G} 3$ powder lot on the upper end and by the $\mathrm{C} 1$ powder lot on the lower end. Again, the B1 powder lot displays the strongest response (1439 MPa) and the E1 lot the weakest $(1276 \mathrm{MPa})$. The tensile strength is found to be inversely proportional to the amount of cross-hatching appearing on the fracture surfaces, with the E1 bars exhibiting extensive cross-hatching that covered the majority of the fracture surfaces.

The outlier responses in B1 and E1 build strength may be explained by differences in 718 powder composition (Table 1) and carbide distributions (Table 2), and the resulting effect on the $\gamma^{\prime \prime}\left(\mathrm{Ni}_{3} \mathrm{Nb}\right)$ and $\gamma^{\prime}\left(\mathrm{Ni}_{3} \mathrm{Al}\right.$, Ti) distributions as primary particle strengtheners. In addition to solid solution strengthening, $\mathrm{Nb}$ partitions strongly to the MC-carbides and $\gamma$ "-precipitates in Alloy 718. The B1 powder lot contains 4.5 to 10 times less $\mathrm{C}$ leading to 4 to 50 times lower $\mathrm{V}_{\mathrm{f}}$ of carbides compared to the group. The much lower carbide $\mathrm{V}_{\mathrm{f}}$ of $0.002 \%$ leads to a higher supersaturation of $\mathrm{Nb}$ in solution to form $\gamma^{\prime \prime}\left(\mathrm{Ni}_{3} \mathrm{Nb}\right)$ precipitates; accordingly, the $\gamma^{\prime \prime}\left(\mathrm{Ni}_{3} \mathrm{Nb}\right)$-precipitates from heat-treated $\mathrm{B} 1$ build set are coarser at similar number densities to the rest of builds, which contributes to the higher strength. In contrast, the E1 powder contains 2 to 4.5 times more $\mathrm{C}$ leading to 2.5 to 28 times higher $\mathrm{V}_{\mathrm{f}}$ of carbides, and a lower number density of $\gamma^{\prime \prime}\left(\mathrm{Ni}_{3} \mathrm{Nb}\right)$-precipitates, contributing to its lower strength. The $\mathrm{E} 1$ powder also contains significantly less $\mathrm{Al}$ at $0.09 \mathrm{wt} . \%$ ( 0.2 to $0.8 \mathrm{wt} . \%$ is required by AMS 5664) than the other powders, which typical contained $\sim 0.4 \mathrm{wt} \% \mathrm{Al}$. The Al deficiency in E1 powder leads to fewer $\gamma^{\prime}\left(\mathrm{Ni}_{3} \mathrm{Al}, \mathrm{Ti}\right)$-precipitates to strengthen the E1 build. The next four build sets with the lowest strengths (AF UTS of $1265-1285 \mathrm{MPa}$ and LSG UTS of 1333 - $1342 \mathrm{MPa}$ ) are from the $\mathrm{C} 1, \mathrm{H} 1$, and E2 virgin and once-recycled powders, which includes the builds with the highest $\mathrm{N}$ contents due to their atomization in $\mathrm{N}$. This result is somewhat surprising as the refined grain sizes of this group (19-41 $\mu \mathrm{m}$ compared to 51-90 $\mu \mathrm{m}$ mean linear intercept) and narrow grain widths in loading is expected to lead to strengthening. Further work is needed to understand the mechanism that contribute to the weaker response of this fine-grained group with a high nitrogen concentration. It may relate to less strengthening due to fewer $\gamma^{\prime}\left(\mathrm{Ni}_{3} \mathrm{Al}\right.$, Ti)-precipitates forming with less Ti available after partitioning to nitrides during solidification. It may relate to a degradation in GB strength due to increased concentration of minor phases at the GBs. As noted above, the $\mathrm{H} 1$ test bars are unique due to their atypical surface condition, which may also be responsible for its weaker response.

As shown in Table 3, the $0.2 \%$ yield strength, UTS, elongation to failure and reduction in area meets or exceeds the minimums given by AMS 5664 for solution and aged bars, except for the AF condition for the E1 and E2 powder lots. The E2-R powder lot barely meets the requirements with the slight bump in strength that is observed with first recycling. An average over all samples shows an elastic modulus of 186 GPa. For each property within Table 3, the SLM materials tested in the AF condition are slightly lower than the materials from the LSG condition. Strengths and stiffness differ by $4 \%$ and ductility varies by a wider margin. The lower values in strength and stiffness may be a result of overestimating the crosssectional area of the AF test bars due to the rough surfaces with fused particles. The lower ductility for the AF tests is presumed to be a result of the surface defects associated with the AF surface condition.

Like the tensile testing, the HCF tests on SLM 718 with AMS 5664 heat treat were run at room temperature for the AF and LSG surface conditions for all powder lots. Three tests were run for each surface condition per lot with an extra test for the E2 powder lot in the AF condition. Figure 8 compares the mean fatigue lives $\left(N_{f}\right)$ as bar charts and individual tests as 


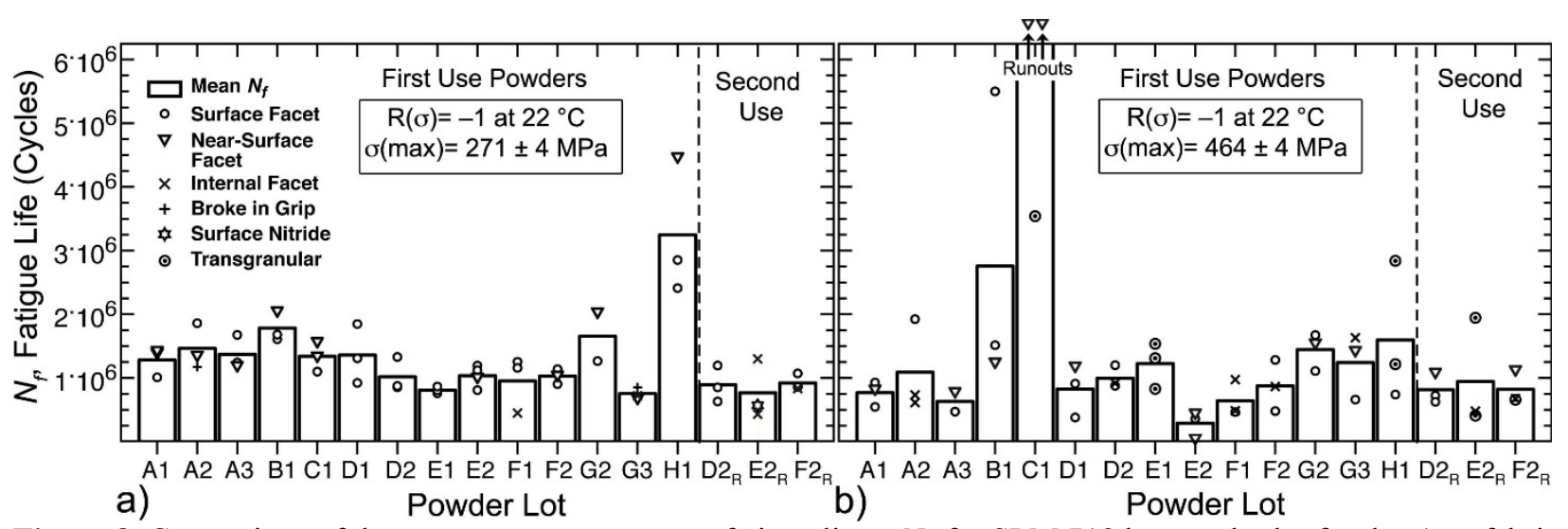

Figure 8. Comparison of the room temperature mean fatigue lives, $N_{f}$, for SLM 718 by powder lot for the a) as-fabricated and b) low stress ground surface conditions. Markers indicate crack initiation mechanisms and each test result. Mean $N_{f}$ are statistically equivalent for once-recycled $(\mathrm{R})$ lots and virgin equivalents.

markers that also indicate the crack initiation mechanism identified from the fracture surfaces. The maximum stress to achieve about million cycle average for the LSG test bars is $464 \mathrm{MPa}$; the LSG testing results are in reasonable agreement with wrought 718 with AMS 5664 heat treat from the literature [13], indicating consistent material properties and SLM fabrication is reasonable to process for Alloy 718 . The roughness of the AF surface led to a $\sim 40 \%$ knock down in maximum stress to $271 \mathrm{MPa}$ for the $\mathrm{AF}$ condition to achieve the similar million cycle average. It is worth noting that the restart procedure used is effective at retaining material integrity, as only two of the 102 test results are excluded (AF G2-1, LSG A3-8) because the bars failed at poorly bounded layers (major lack of fusion) at a restart layer. The gauge, radius and grips of the test bars are single-build SLM 718. Tests bars A2-1 and G3-5 with the AF surfaces broke in the grip section and show fatigue lives consistent with the other two tests from these build sets; all other test bars failed in the gauge section.

The room temperature HCF behavior for the AF surface condition are fairly consistent across powder lots except for the H1 powder lot (Fig. 8). The AF tests show fatigue lives that span from 0.6-1.8 million cycles for most tests (Fig. 8a), which overlap statistically on cumulative probability plots for all powder lots except for the H1 powder lot. The mean life of test bars fabricated from the second-use the D2, E2, F2 are statistically equivalent to, though in most case lower than, the mean life of the first-use powder samples. This suggests that for SLM 718 the first recycle does not substantially degrade the room temperature $\mathrm{HCF}$ lives. The $\mathrm{H} 1$ bars tested in the $\mathrm{AF}$ condition represent an obvious outlier with fatigue lives lasting well above 2 million cycles for all three tests and this is examined further below. The scatter by powder lot between the lowest and highest values in fatigue lives for AF tests is reasonable with scatter: less than 1.5 for more than half of the build sets, less than 2 for most powder lots, and about 3 for only the F1 and E2-R build sets.

Failure sites are identified from the fracture surfaces with SEM for each test bar to better understand the failure modes (Fig. 8). The fatigue failures of the AF bars initiate overwhelming, 48 of 49 non-grip failures, at facet failures within grains, which fail in crystallographic manner due to concentrated slip at a cleavage plane. Figure 9 shows the four types of facet failures observed: a) surface facet; b) surface facet with additional crystallographic steps; c) near-surface facet (within $~ 200$ $\mu \mathrm{m})$; d) internal facet. The failure site for the E2-R-1 test bar is a $50 \mu \mathrm{m}$ nitride near the surface instead of a facet (Fig. 9e). The additional crystallographic steps with some facet failures, such as shown in Fig. 9b, are observed for one or two tests in every powder lot that was fully recrystallized (A, B, D, F, G series). These recrystallized conditions produce larger grains with fewer minor phases at the GBs that presumably have poorer resistance to crack growth than GBs reinforced with minor 


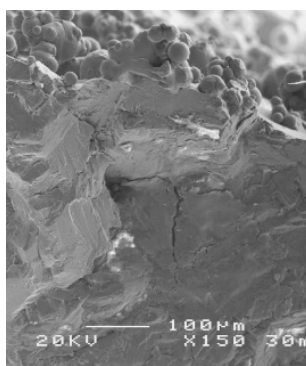

a)

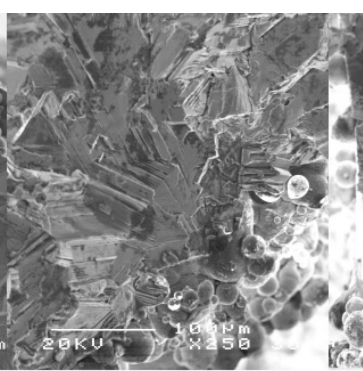

b)

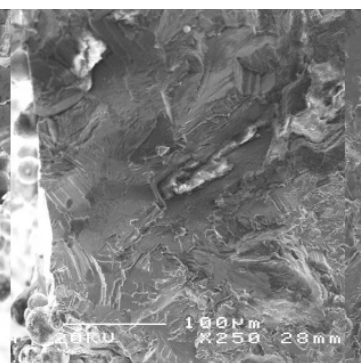

c)

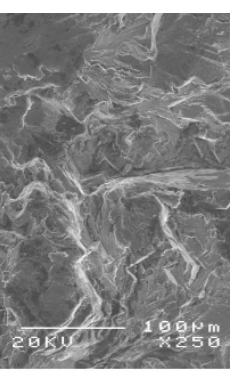

d)

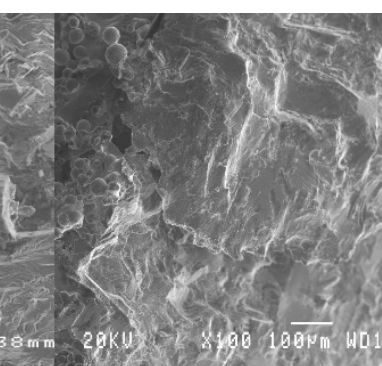

e)

Figure 9. Representative failure sites observed for heat treated SLM 718 with the as-fabricated (AF) surface finish showing initiation by a a) surface facet; b) surface facet with additional crystallographic steps; c) near-surface facet (within $\sim 200 \mu \mathrm{m}$ ); d) internal facet; e) large $50 \mu \mathrm{m}$ nitride (dark contrast). The powder lots show statistically equivalent fatigue lives for the AF condition except H1 (see Figure 7a).

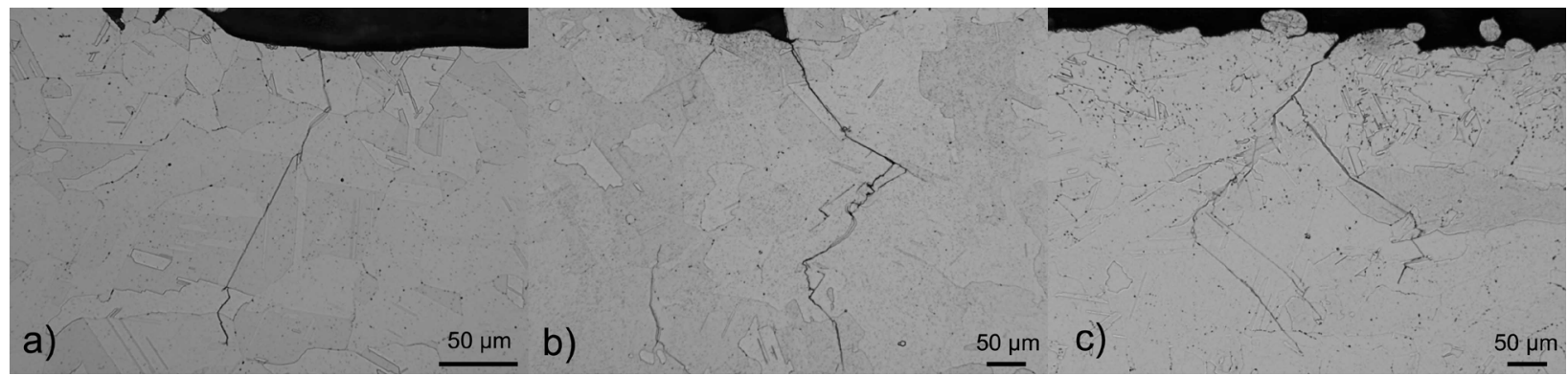

Figure 10. Representative secondary crack sites observed for heat treated SLM 718 test bars a) B1-1, b) F1-1, and c) G2-3 with the AF surface finish showing some initiations at surface asperities and transgranular crack propagation after initiation.

phases. The steps may result from persistent slip bands associated with strain localization during Stage I crack propagation under these conditions (see review by Jiang [17]). Notably, 90\% of the tests failed at the surface (30 tests) or within a few grains from the surface (14 tests) with only 5 tests initiating at internal facets for the AF condition. The failure sites for the AF condition are sometimes in the vicinity of a surface step, cusp or depression as shown for representative cross-sectional images of secondary crack (Fig. 10). With the longitudinal ridges (Fig. 7a-b), the inherent rough surface and fused particles, all the test bars have a high number of stress concentrators and stress gradients that decay from the surface. The statistically equivalent fatigue lives across powder lots implies that these stress concentrators, which are common to all test bars, have a greater influence on fatigue life in the AF condition than variations in powder attributes, composition or build microstructure. Cracks tend to propagate transgranularly after initiation (Fig. 10).

For the AF surface condition, the H1 lot showed significantly better fatigue lives than the all other powder lots (Fig. 8a). Cracks initiated from facets just as discussed above. For example, the AF H1-5 fracture surface shows a deep surface depression initiating failure at three closely spaced facets (Fig. 11a), where the crack then propagates transgranularly from a single site (Fig. 11b). The longest life of all the AF tests is 4,477,340 cycles to failure for the H1-1 test bar; for this test, the crack initiated from a sub-surface facet that was fairly average in size at $30 \mu \mathrm{m}$ diameter with respect to grain distribution (Fig. 11c). Facet failures are commonly recorded for coarser-grained polycrystalline Ni-based superalloys (grain size of $\sim 50 \mu \mathrm{m}$ ), with the failures initiating at grains that are properly oriented for slip and are relatively large with respect to the average grain size [18]. The grain sizes for the builds investigated here are all fairly coarse, so it is not surprising to observe 


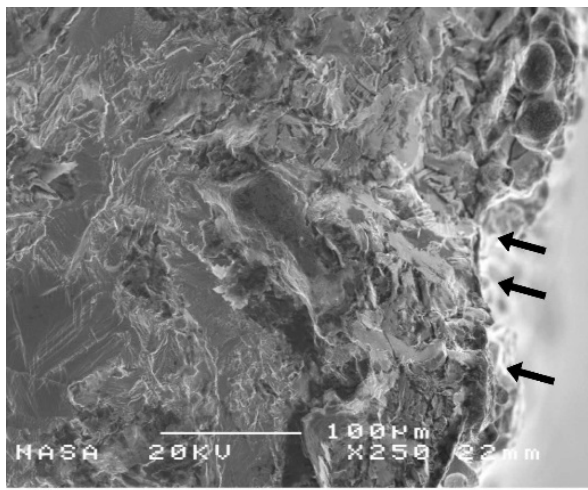

a)

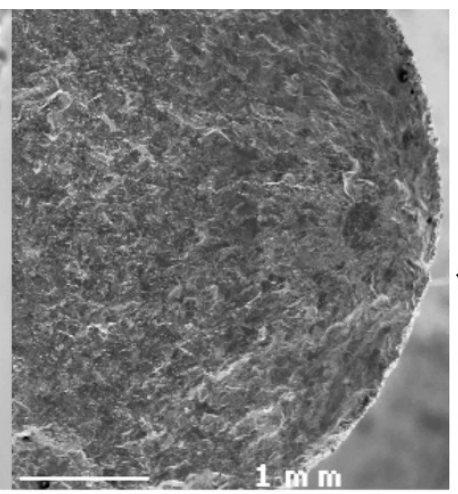

b)

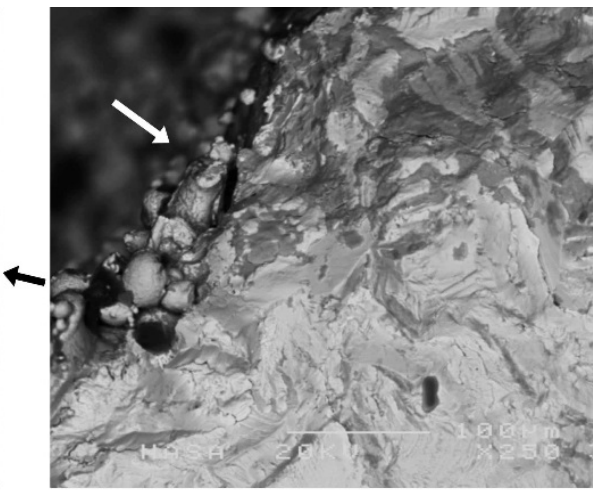

c)

Figure 11. For the H1-5 test with a $N_{f}=2,852,066$ cycles, the a) crack initiated from three closely spaced facets at or near the surface from $b$ ) a single primary failure site that is located adjacent to step in the surface and propagated transgranularly. For the H1-1 test with a $N_{f}=4,477,340$ cycles, the c) single failure site is a facet about $100 \mu \mathrm{m}$ beneath the surface. Most fracture surfaces exhibit some oxide from contact debris (grey contrast) and some carbon contamination (dark contrast) like for the H1-1 surface.

facet failures. Perhaps failures are initiated at average-sized grains rather than large grains due to the influence of stress concentration fields from features associated with the rough SLM surface compared to the well-oriented coarse-grains within the test bar. It is worth noting that LSG test results for $\mathrm{H} 1$ powder lot do not standout like the AF test results (Fig. 8b); this suggests that the high fatigue lives for AF condition is surface-related and not inherent to the material properties. A unique feature of the $\mathrm{H} 1$ powder is that it contained over $70 \%$ particle fines on a number basis and experienced a high degree of agglomeration (Figure 1b). This unique distribution may influence the surface topology and, in turn, the sources of fatiguelimiting stress concentration that drive the fatigue behavior. Compared to a F1 test bar imaged (Fig. 7c), the H1 test bar does appear qualitatively to have more sparse population of unmelted particles on the surface (Fig. 7d). Another unique feature of the $\mathrm{H} 1$ test bars is the high number density of $(\mathrm{Nb}, \mathrm{Ti})$-based particles present on the surfaces that also appears to be linked to an unusual grey surface color. These particles and surface discoloration are believed to result of an unknown reaction / contamination during the HIP heat treatment, it is plausible that the compositional changes associated with these changes improved the fatigue resistance. Further investigation is needed to determine which unique feature led to improved fatigue properties for the AF surface condition.

The fatigue tests of the LSG surface condition result in more variation than occurred in the AF surface condition, Fig. 8b. The cycles-to-failure mean value ranged from 0.29 to 6.86 million cycles for the LSG condition, but only 0.71 to 1.46 million cycles for the AF condition excluding H1. For the LSG condition, there is also a slightly larger range in individual fatigue lives from 0.4 to 2.0 million cycles for most tests. The $\mathrm{C} 1$ is a clear outlier as the best performer with 2 runouts and test bar that failed at 3,540,392 cycles, which is well above this range. For the B1 and H1 powder lots, each had a single test that was higher than the group range with failed tests at $N_{f}=5,500,000$ cycles and at 3,540,392 cycles, respectively. The mean fatigue lives for the LSG tests for B1 of $N_{f}=2.76$ million cycles and E2 of $N_{f}=0.29$ million cycles are distinctly higher and lower than the group that excludes outlier $\mathrm{C} 1$. Compared to the AF tests, there is a larger degree of scatter between the highest and lowest values by lot for the LSG tests with only one powder lot with scatter less than 1.5, with four lots with 
scatter between 2 and 3 and five lots with scatter above 3. Additional tests are required to better establish the mean fatigue lives and trends. Like for AF testing, recycling once does not appear to degrade substantially the fatigue lives; the virgin E2 tests on average are three times lower than the mean for the first recycled equivalent, which may be related to the larger scatter.

Moreover, the crack initiation mechanisms for the LSG surface condition also show more variation than the AF surface condition, Fig. $8 \mathrm{~b}$ and Fig. 12. Similar to the AF tests, the highest percentage of the failure initiations are surface or nearsurface facets, but only $63 \%$ for the LSG tests compared to $90 \%$ for the AF tests. The number of failures initiated at internal facets is nearly double with 9 internal facet failures for the LSG condition compared to 5 for the AF condition. With the rough surface removed, the facet failures appear to initiate at larger than average grains, as shown in Fig. 12. These internal, subsurface, and surface failures occurred at grains that are about double the mean grain size of $92 \mu \mathrm{m}, 63 \mu \mathrm{m}, 41 \mu \mathrm{m}$ for the respective powder lots F1, G2 and H1. In contrast to the AF failures, transgranular initiations (Fig. 12d) compete with facet failures in the finer grained LSG test bars from the C1, H1, E1, E2-R powder lots with 10 tests recorded. Within the C1 powder lot, the two run-out tests failed ultimately from sub-surface facets, while the test that reached 3,540,382 cycles failed transgranularly. Grain boundary resistance in adjacent grains surrounding the failed facet grain is important to initial propagation during Stage I crack propagation. The superior fatigue lives for the C1 LSG condition are likely linked to the very fine distribution of carbides and nitrides along the GBs that provide strengthening and retard early-stage crack propagation. In the E series, the GB carbides are much larger and more sparsely distributed than in the $\mathrm{C} 1$ build and thus provides less GB strength and resistance to early-stage propagation than the fine minor phase distribution for $\mathrm{C} 1$. The higher mean fatigue results for the B1 condition with the LSG surface finish may be linked to higher tensile strength provided by the coarser $\delta$-precipitates that may lead to improved fracture strength. Overall, the room temperature fatigue behavior of the low stress ground test bars is much more sensitive to the microstructural variations between the powder lots than the bars tested in the as-fabricated condition.

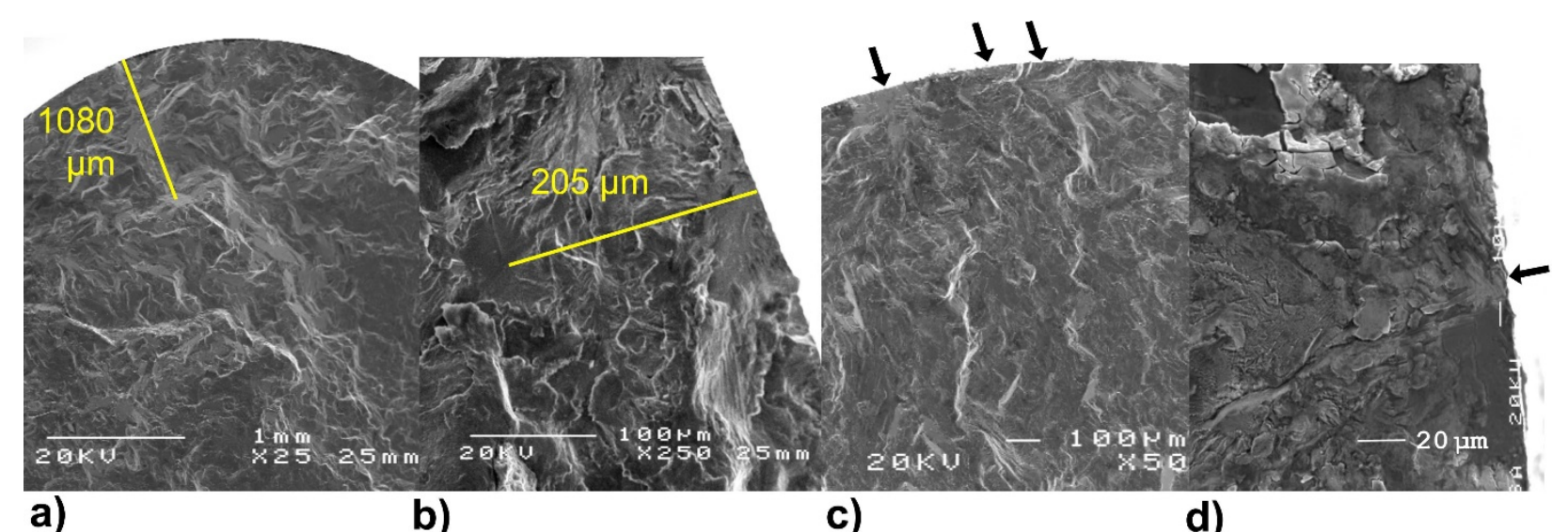

a)

b)

c)

d)

Figure 12. Fracture surfaces for the LSG test bars showing initiation by a) an internal facet (F1-4: $N_{f}=975,010$ cycles); b) a sub-surface facet (G2-6: $N_{f}=1,554,136$ cycles); c) three closely spaced surface facets (H1-8: $N_{f}=739,916$ cycles); d) surface transgranular site (C1-6: $N_{f}=3,540,382$ cycles). 


\section{Summary and Conclusions}

An investigation of the impact of powder variability on microstructure, room temperature tensile and HCF behavior was performed on material produced by selective laser melting (SLM) of Alloy 718. The sixteen commercially available powder lots were produced either by gas atomization or rotary atomization in argon or nitrogen (Table 1), were heat treated per AMS 5664, and made into uniform gauge test bars. The following summary and conclusions were observed:

- All these "off-the-shelf" Alloy 718 powders were spheroidal and highly regular in shape. The differences in powder production practices, however, did lead to variation in average diameters, particle size distribution widths and modalities, percentage of particle fines, fusion between particles, and degree to which the powders were agglomerated (Fig. 2, Fig. 3, and Table 1). The powders with higher quantity of fines and agglomeration were more prone to unplanned stops during SLM fabrication. These fabrication difficulties led to layer discontinuities that were likely due to differences in spreading behavior of the powders (Fig. 1).

- The majority of the powders demonstrated tight composition control that led to consistent tensile behavior, which may be attributed to similar distributions of strengthening precipitates (Table 3). The trace nitrogen content varied according to powder processing practices with gas atomization in $\mathrm{N}$ producing powders with the highest $\mathrm{N}$ contents (Table 1). The "E" supplier was the only supplier with poor compositional control. One "E" powder lot had lower Al and higher $\mathrm{C}$ contents than specified for Alloy 718. The second "E" lot did meet the compositional specification, however its composition fell outside the common composition grouping for $\mathrm{Al}$ and $\mathrm{C}$ (Table 1). The lot procured from the "B" supplier consisted of powder intentionally low in C content and resulted in the best tensile properties (Table 3); this was attributed to more $\mathrm{Nb}$ available for particle strengthening.

- The NASA MSFC developed SLM processing parameters produced quality builds with modest amounts of micron sized pores that were further reduced through HIP heat treatment to less than 0.02 percent porosity and an average pore diameter of less than $4.5 \mu \mathrm{m}$ (Table 2). The tensile properties of the various SLM 718 builds met or exceeded the AMS 5664 specified minimum values. The HCF lives and failures modes agreed with conventionally processed 718 and common artifacts often associated with SLM fabrication (e.g. lack of fusion, trapped unmelted particles, boundaries between contours and bulk) did not appear to initiate fatigue failure. The layer discontinuities within all test bars due to planned and unplanned restarts were effectively mitigated using a restart procedure developed at NASA MSFC and rarely initiated HCF failure.

- Material produced from the Ar-atomized powder experienced recrystallization of the scalloped (001)-textured grains after high temperature heat treatments. Randomly-oriented, equiaxed grains with an average size that ranged from 51 $\mu \mathrm{m}$ to $90 \mu \mathrm{m}$ (Table 2) resulted when the starting powder had $\mathrm{N}$ content less than $\sim 600 \mathrm{wt} . \% \mathrm{ppm}$ and had C contents within specification. A single Ar-atomized powder lot from the "H" supplier with $567 \mathrm{wt} \% \% \mathrm{ppm} \mathrm{N}$ experienced partial recrystallization, which resulted in a mix of fine and large grained areas. SEM-EDS examination was inconclusive in determining the origin of the partial grain boundary pinning; however, the powder dynamics in the melt pool between the extraordinarily high percentage of fines $(\sim 75 \%)$ in this particular powder and its regular-sized particles may play a role (Fig. 4). 
- Material produced from the three $\mathrm{N}$-atomized powders were not recrystallized and retained the scalloped grain structure (Fig. 4) due to grain boundary pinning by minor phases. Powder from supplier "C" produced a fine distribution of TiNnitrides and MC-carbides that decorated the grain boundaries in the fully heated material (Fig. 6b); these particles were attributed to their formation on particles surfaces during atomization, known in the literature as prior particles. These prior particles led to superior room temperature HCF performance for machined surfaces (Fig. 8b), which is attributed to improved resistance to early-stage crack propagation by the decorated grain boundaries. Powder from supplier E produced material that did not perform particularly well in HCF testing conditions despite its fine grain structures. The grain boundaries for these powder lots were pinned by coarser MC-carbides and did not contain the fine decoration of particles that helped stabilize the grain boundaries from early-stage crack propagation.

- Strength and ductility were not degraded significantly after one-reuse powder recycling (Table 3 ); in fact tensile strength improved slightly and the HCF behavior was comparable (Figure 8). This suggests that degradation in properties due to powder recycling may be less of an issue for Ni alloys like Alloy 718 than for other alloys systems.

- As expected, the as-fabricated (AF) specimens had lower fatigue lives but also less scatter in HCF response compared to the low stress ground (LSG) surfaces (Fig. 8). The predominant failure sites for both conditions were grain facets at or near the surface (Fig. 9, Fig. 11, and Fig. 12). The percentage of surface failures was significantly higher for AF surfaces due to stress concentrators associated with SLM surface asperities (Fig. 10). The high concentration of stress at AF surfaces led to facet failures that originated from average-sized grains (Fig. 9 and Fig. 11), whereas the LSG failures often initiated at larger than average-sized grains (Fig. 12).

\section{Acknowledgments}

The authors would like to acknowledge NASA MSFC engineers Kristin Morgan for some project development and establishing funding, William Tilson for HIP and heat treatment coordination, Richard Boothe for Malvern Morphologi data acquisition, Kenneth Cooper for the SLM fabrication coordination, Brian West for general coordination with MSFC personnel. These engineers, Douglas Wells from NASA MSFC, Dr. Jonathan Woolley from NASA MSFC, and Robert Carter from NASA GRC are also acknowledged for useful discussions. The authors would like to also acknowledge experimental support from the staff with the NASA MSFC Advanced Manufacturing and Heat Treat Facilities, GRC Analytical Sciences Group, GRC Mechanical Testing Facility, and GRC student interns Alejandro Hinojos, Paul Chao, Michael Kloesel, Bethany Cooke and Jonathan Healy. The authors would also like to acknowledge Dr. Cheryl Bowman for review of this manuscript. Funding was received from NASA Space Launch Liquid Engine with the Additive Manufacturing Structural Integrity Initiative Project under NASA Human Exploration and Operations Mission Directorate.

\section{References}

[1] R. P. Jewett and J. A. Halchak, "The Use of Alloy 718 in the Space Shuttle Main Engine," in Superalloys 718, 625, and Various Derivatives, Warrendale, PA, 1991.

[2] D. F. Paulonis, J. M. Oblak and D. S. Duvall, "Precipitation in Nickel Alloy 718," Transactions of ASM, vol. 60, pp. 611-622, 1969.

[3] J. F. Radavich, "The physical metallurgy of cast and wrought Alloy 718," in Superalloy 718-Metallurgy and Applications, Warrendale, PA, 1989. 
[4] M. Sundararaman, P. Mukhopadhyay and S. Banerjee, "Carbide precipitation in nickel base superalloys 718 and 625 and their effect on the mechnical properties," in Superalloys 718, 625, 706 and Various Derivatives, Warrendale, PA, 1997.

[5] R. C. Reed, The Superalloys: Fundamentals and Applications, Cambridge: Cambridge University Press, 2008.

[6] Z. Wang, K. Guan, M. Gao, X. Li, X. Chen and X. Zeng, "The microstructure and mechanical properties of deposited-IN718 by selective laser melting," Journal of Alloys and Compounds, vol. 513, pp. 518-523, 2012.

[7] K. N. Amato, S. M. Gaytan, L. E. Murr, E. Martinez, P. W. Shindo, J. Hernandez, S. Collins and F. Medina, "Microstructure and mechanical behavior of Inconel 718 fabricated by selective laser melting," Acta Materialia, vol. 60, pp. 2229-2239, 2012.

[8] L. L. Parimi, G. A. Ravi, D. Clark and M. M. Atallah, "Microstructural and texture development in direct laser fabricated IN718," Materials Characterization, vol. 89, pp. 102-111, 2014.

[9] M. E. Aydinöz, F. Brenne, M. Schaper, C. Schaak, W. Tilmann, J. Nellesen and T. Niendorf, "On the microstructural and mechanical properties of post-treated additively manufactured Inconel 718 superalloy under quasi-static and cyclic loading," Materials Science and Engineering: A, pp. 246-258, July 2016.

[10] E. Chelbus, K. Gruber, B. Kuznicka, J. Kurzac and T. Kurzynowski, "Effect of heat treatment on the microstructure and mechanical properties of Inconel 718 processed by selective laser melting," Materials Science and Engineering: $A$, vol. 639, pp. 647-655, 2015.

[11] M. Seifi, A. Salem, J. Beuth, O. Harrysson and J. J. Lewandowski, "Overview of Materials Qualification Needs for Metal Additive Manufacturing," JOM, vol. 68, no. 3, pp. 747-764, March 2016.

[12] D. Wells, "Engineering and Quality Standard for Additively Manufactured Spaceflight Hardware- Draft," National Aeronautics and Space Administration, Huntsville, AL, 2017.

[13] C. K. Sudbrack, D. L. Ellis, B. A. Lerch, T. M. L. I. E. Smith, A. C. Thompson, J. M. Tylka, W. Tilson, R. E. Boothe, K. F. Cooper, B. Richards, P. Chao, A. Hinojos and M. Kloesel, "Industry comparison of powder variability of selective laser melted Ni-based superalloy 718," In preparation, National Aeronautics and Space Administration, Washington DC, 2018. https://ntrs.nasa.gov/

[14] L. M. Sochalski-Kolbus, E. A. Payzant, P. A. Cornwell, T. R. Watkins, S. S. Babu, R. R. Dehoff, M. Lorenz, O. Ovchinnikova and C. Duty, "Comparison of Resididual Stresses in Inconel 718 Simple Parts Made by Electron Beam Melting and Direct Laser Metal Sintering," vol. 46A, pp. 1419-1431, 2015.

[15] F. J. Rizzo and J. J. Conway, "Investigation of nitrogen atomized PM Alloy 625," in Superalloys 718, 625, 706 and Various Derivatives, Pittsburgh, PA, 1994.

[16] G. E. Fuchs and S. Z. Hayden, "The microstructure and tensile properties of nitrogen containing vacuum atomised Alloy 690," Scripta Metallurgica et Materialia, vol. 25, pp. 1483-1488, 1991.

[17] R. Jiang, Study of Fatigue Crack Initiation and Propagation Mechanisms in an Advanced Ni-based Superalloy: Effects of Microstructures and Oxidation, Southhampton: University of Southhampton, 2015.

[18] T. P. Gabb, P. T. Kantzos, J. Telesman, J. Gayda, C. K. Sudbrack and B. Palsa, "Fatigue resistance of the grain size transition zone in a dual microstructure superalloy disk," International Journal of Fatigue, vol. 33, pp. 414-426, 2011. 